\title{
Detrimental role of prolonged sleep deprivation on adult neurogenesis
}

\author{
Carina Fernandes ${ }^{1,2}$, Nuno Barbosa F. Rocha ${ }^{3}$, Susana Rocha ${ }^{4}$, Andrea Herrera-Solís ${ }^{5}$, \\ José Salas-Pacheco ${ }^{6}$, Fabio García-García ${ }^{7}$, Eric Murillo-Rodríguez ${ }^{8}$, Ti-Fei Yuan $^{9}$, \\ Sergio Machado ${ }^{10,11}$ and Oscar Arias-Carrión ${ }^{5 *}$

\begin{abstract}
${ }^{1}$ Faculty of Medicine, University of Porto, Porto, Portugal, ${ }^{2}$ Laboratory of Neuropsychophysiology, Faculty of Psychology and Education Sciences, University of Porto, Porto, Portugal, ${ }^{3}$ School of Health Technologies, Polytechnic Institute of Porto, Porto, Portugal, ${ }^{4}$ School of Accounting and Administration of Porto, Polytechnic Institute of Porto, Porto, Portugal,

${ }_{5}^{5}$ Unidad de Trastornos del Movimiento y Sueño, Hospital General Dr. Manuel Gea González/Instituto de Fisiología Celular, Universidad Nacional Autónoma de México, Mexico City, Mexico, ${ }^{6}$ Instituto de Investigación Científica, Universidad Juárez del Estado de Durango, Durango, Mexico, ${ }^{7}$ Departamento de Biomedicina, Instituto de Ciencias de la Salud, Universidad Veracruzana, Xalapa, Mexico, ${ }^{8}$ División Ciencias de la Salud, Laboratorio de Neurociencias Moleculares e Integrativas, Escuela de Medicina, Universidad Anáhuac Mayab, Mérida, México, ${ }^{9}$ School of Psychology, Nanjing Normal University, Nanjing, China, ${ }^{10}$ Panic and Respiration, Institute of Psychiatry of Federal University of Rio de Janeiro, Rio de Janeiro, Brazil, 11 Physical Activity Neuroscience, Physical Activity Sciences Postgraduate Program, Salgado de Oliveira University, Niterói, Brazil
\end{abstract}

\section{OPEN ACCESS}

Edited by:

Dirk M. Hermann,

University Hospital Essen, Germany

Reviewed by:

Luca Peruzzotti-Jametti,

University of Cambridge, UK Maria Vittoria Podda,

Università Cattolica del Sacro Cuore,

Italy

Marta Pace

University of Bern, Switzerland

*Correspondence:

Oscar Arias-Carrión

Unidad de Trastornos del Movimiento y Sueño, Hospital General Dr. Manuel Gea González/Instituto de Fisiología

Celular, Universidad Nacional

Autónoma de México, Calzada de Tlalpan 4800, Delegación Tlalpan, 14080 Mexico City, Mexico arias@ciencias.unam.mx

Received: 12 November 2014 Accepted: 24 March 2015 Published: 14 April 2015

Citation:

Fernandes C, Rocha NBF, Rocha S, Herrera-Solís A, Salas-Pacheco J, García-García F, Murillo-Rodríguez E, Yuan T-F, Machado $S$ and Arias-Carrión O (2015) Detrimental role of prolonged sleep deprivation on adult neurogenesis. Front. Cell. Neurosci. 9:140. doi: 10.3389/fncel.2015.00140
Adult mammalian brains continuously generate new neurons, a phenomenon called adult neurogenesis. Both environmental stimuli and endogenous factors are important regulators of adult neurogenesis. Sleep has an important role in normal brain physiology and its disturbance causes very stressful conditions, which disrupt normal brain physiology. Recently, an influence of sleep in adult neurogenesis has been established, mainly based on sleep deprivation studies. This review provides an overview on how rhythms and sleep cycles regulate hippocampal and subventricular zone neurogenesis, discussing some potential underlying mechanisms. In addition, our review highlights some interacting points between sleep and adult neurogenesis in brain function, such as learning, memory, and mood states, and provides some insights on the effects of antidepressants and hypnotic drugs on adult neurogenesis.

Keywords: sleep, adult neurogenesis, hypnotic drugs, antidepressants, circadian rhythms, hippocampus

\section{Introduction}

Thousands of new neurons are daily added to the adult brain of different species, including humans (Yuan et al., 2014), and this constant lifelong generation implies significant structural changes (Eriksson et al., 1998; Curtis et al., 2007). Neurogenesis is involved in numerous brain processes but its association with sleep deprivation was only recently addressed. Previous research has focused on how generation and development of new neurons are affected by sleep loss. Short periods of sleep deprivation do not significantly alter the basal rate of cell proliferation, whereas long periods result in a decrease of cell proliferation and survival in the hippocampus (Mirescu et al., 2006). In this review, we will discuss the possible effects of sleep deprivation on the natural course of neurogenesis, and address the potential connections between sleep and neurogenesis that may influence other cognitive and neuropsychobiological functions, such as learning, memory, and mood disorders. 


\section{Adult Neurogenesis}

Neurogenesis includes the generation, proliferation, fate specification and integration of new functional neurons in the existing neural circuits from undifferentiated progenitor cells. Traditionally, it was believed that neurogenesis mainly occurred during the embryonic stages of the central nervous system (CNS), ending permanently at puberty (Ming and Song, 2005; Meerlo et al., 2009).

New findings, based on techniques such as $\left[{ }^{3} \mathrm{H}\right]$-thymidine autoradiography (Sidman et al., 1959) and 5-bromo-2'deoxyuridine (BrdU; Nowakowski et al., 1989), which mark cells in S phase of mitosis, electronic microscopy (Kaplan, 1977, 1981, 1984, 1985) and combining retroviral-based lineage tracing with electrophysiological methods (Sanes et al., 1986; Price et al., 1987) revealed the continuous adult neurogenesis and synaptic integration. Newborn neurons were found in certain CNS regions of birds (Goldman and Nottebohm, 1983), rats (van Praag et al., 1999), monkeys (Kornack and Rakic, 1999), and humans (Eriksson et al., 1998; Curtis et al., 2007), throughout life.

Neurogenesis occurs in specific areas of the CNS, namely in the subventricular zone (SVZ), lining the wall of the lateral ventricles, and in the subgranular zone (SGZ) of the hippocampal dentate gyrus (Alvarez-Buylla and Lim, 2004). The neurogenic behavior of these areas appears to be determined by signals of endothelial cells and astrocytes (Alvarez-Buylla and Lim, 2004).

Similarly, a cohort of glucogenic and neurogenic signals (Lim et al., 2000) regulates the underlying molecular mechanisms of neuronal differentiation, fate specification (Ming and Song, 2005; Arias-Carrión et al., 2007; Yuan and Arias-Carrion, 2011; Höglinger et al., 2014) and migration of new generated cells (Hu et al., 1996; Conover et al., 2000; Murase and Horwitz, 2002; Bolteus and Bordey, 2004). Newly formed neurons in the SVZ reach the olfactory bulb, by the rostral migratory stream (Saghatelyan et al., 2004), forming granule and periglomerular neurons. These neurons establish dendro-dendritic synapses with tufted cells (Abrous et al., 2005), beginning a maturation process by receiving GABAergic and glutamatergic synaptic inputs (Belluzzi et al., 2003). When maturate, the granule neurons secrete GABA, while periglomerular neurons secrete GABA and dopamine (Wang et al., 2000; Arias-Carrión et al., 2007). In the dentate gyrus, newborn neurons reach the anterior layer of the granule cells (Hastings and Gould, 1999), maintaining their neuronal maturation and synaptogenesis over several months (van Praag et al., 2002). It is believed that these neurons receive initially GABAergic and later glutamatergic inputs (Ming and Song, 2005). Once mature, most of these neurons secrete glutamate, while a small population releases GABA (Wang et al., 2000).

Adult neurogenesis is modulated by intrinsic and extrinsic factors (Table 1), being possible that several modulating factors remain unknown (Kempermann, 2002).

\section{Sleep-Wake Cycle Regulation}

Sleep and wakefulness are rhythmic behaviors regulated by circadian rhythms (Murillo-Rodríguez et al., 2009; Arias-Carrión et al., 2011). Wakefulness is a state of full manifestation of perceptual-sensory and voluntary motor activity (Siegel, 2001; Murillo-Rodríguez et al., 2009). Sleep is characterized by a rapid reversibility, reduced motor activity, responsiveness and metabolism (Siegel, 2009) and can be divided into distinct stages, cyclically repeated: the rapid eye movement sleep (REMS) and non-REM sleep (NREMS; Murillo-Rodríguez et al., 2009; AriasCarrión et al., 2011; Ruehland et al., 2011). There are evidences that sleep plays an essential role in learning and memory (Keisler and Willingham, 2007; Song et al., 2007; Rasch et al., 2008; Rickard et al., 2008; Sheth et al., 2009), regulation of the immune system (Imeri and Opp, 2009; Opp, 2009), reversal of oxidative stress (Eiland et al., 2002) and neurogenesis (Guzman-Marin et al., 2005).

The regulation of sleep-wake cycles can be described by the two-process model, in which one process reflects homeostatic sleep drive, whereas the other is associated to the output of a circadian pacemaker. Combined, the two processes determine the beginning and end of sleep phase: when homeostasis increases above a certain threshold, sleep is triggered; when it drops below a certain threshold, wakefulness occurs. The circadian rhythm is thought to be a daily oscillatory modulator of the two thresholds (Daan et al., 1984).

Internally, the sleep-wake rhythm is centrally coordinated by an endogenous circadian clock, placed in the suprachiasmatic nucleus (SCN) of the anterior hypothalamus (Maywood et al., 2006). The neurons of the SCN are circadian oscillators that form functional pacemakers (Saper et al., 2001; Cheng et al., 2002). The timing of their oscillations is determined by an intrinsic cellular rhythmicity, which lasts $24 \mathrm{~h}$, even in the absence of external inputs (Moore et al., 2002) such as light, feeding patterns, and social environment (Mueller et al., 2013).

\section{Sleep and Neuronal Assemblies}

Despite the existence of a SCN biological clock (Maywood et al., 2006), Krueger et al. (2008) suggest that the global coordination of the NREMS results from an emergent property of local coupled processes in neural networks.

Cortical columns, also called neuronal assemblies, are examples of anatomically well-defined neural networks. It is believed that neuronal assemblies are the basic units of the brain processing during wakefulness, oscillating between functional states such as wake-like and sleep-like states (Rector et al., 2005). During sleep, most neuronal assemblies are in a sleep-like state and, during wakefulness, most of them are in a wakelike state. However, neuronal assemblies in sleep-like state can occur throughout all wakefulness phase and, oppositely, neuronal assemblies in wake-like state may occur during the whole-sleep phase (Krueger et al., 2008). The model of neuronal assemblies suggests that the synchrony between assemblies is a consequence of electrical and hormonal interactions that arise between them. Therefore, networks, that naturally occur with a weak interaction between their components, appear to exhibit emergent properties (collective behaviors that are not easily visible from the individual features of each assembly) that may achieve the 
TABLE 1 | Regulatory factors of adult neurogenesis.

\begin{tabular}{|c|c|c|c|}
\hline Regulatory factors & Implications on adult neurogenesis & Potential mechanisms & Reference \\
\hline Genetic Background & Influence neurogenesis in the SGZ & & Kempermann and Gage (2002) \\
\hline Gender & $\begin{array}{l}\text { Cell proliferation in the SGZ is higher in } \\
\text { females }\end{array}$ & Ovarian hormone levels (estrogen) & Tanapat et al. (1999) \\
\hline Aging & $\begin{array}{l}\text { Decrease cell proliferation in the SVZ } \\
\text { and SGZ }\end{array}$ & Increased levels of corticosteroids & $\begin{array}{l}\text { Kuhn et al. (1996), Cameron and McKay } \\
\text { (2001), Jin et al. (2003), Enwere et al. (2004) }\end{array}$ \\
\hline \multicolumn{4}{|l|}{ Hormones } \\
\hline Estrogen & Stimulate neurogenesis in the SGZ & & Tanapat et al. (1999) \\
\hline Corticosterone & Decrease neurogenesis in the SGZ & $\begin{array}{l}\text { Activation of the } \\
\text { hypothalamic-pituitary-adrenal axis } \\
\text { (HPA) }\end{array}$ & Tanapat et al. (1999) \\
\hline Prolactin & $\begin{array}{l}\text { Stimulate neurogenesis in the SGZ and } \\
\text { SVZ }\end{array}$ & $\begin{array}{l}\text { Activation of the extracellular } \\
\text { signal-regulated kinase } 5\end{array}$ & Tanapat et al. (1999), Wang et al. (2013) \\
\hline \multicolumn{4}{|l|}{ Neurotransmitters } \\
\hline Dopamine & Decrease neurogenesis & Dopamine D2L receptors & $\begin{array}{l}\text { Kempermann (2002), Radley and Jacobs } \\
\text { (2002), Banasr et al. (2004) }\end{array}$ \\
\hline Serotonin & Increase neurogenesis & Serotonin- 1 A receptors & \\
\hline Acetylcholine & Decrease neurogenesis & & \\
\hline Glutamate & Decrease neurogenesis & $\begin{array}{l}\text { Metabotropic glutamate receptors, } \\
\text { NMDA receptors }\end{array}$ & \\
\hline Nitric oxide & Decrease neurogenesis & & \\
\hline Enriched Environments & $\begin{array}{l}\text { Increase the survival of newborn } \\
\text { neurons in the SGZ }\end{array}$ & $\begin{array}{l}\text { Peripheral vascular endothelial } \\
\text { growth factor }\end{array}$ & $\begin{array}{l}\text { Barnea and Nottebohm (1994), } \\
\text { Kempermann et al. (1997), Nilsson et al. } \\
\text { (1999), Brown et al. (2003) }\end{array}$ \\
\hline Physical exercise & $\begin{array}{l}\text { Promote cell proliferation and survival in } \\
\text { the SGZ }\end{array}$ & $\begin{array}{l}\text { Peripheral vascular endothelial } \\
\text { growth factor }\end{array}$ & van Praag et al. (1999), Cao et al. (2004) \\
\hline Physical and psychosocial stress & $\begin{array}{l}\text { Decrease cell proliferation and amount } \\
\text { of new neurons in the SGZ }\end{array}$ & Activation of the HPA & $\begin{array}{l}\text { Gould and Tanapat (1999), Duman et al. } \\
\text { (2001) }\end{array}$ \\
\hline Antidepressants & Increased neurogenesis in the SGZ & Brain-derived neurotrophic factor & Eisch et al. (2000) \\
\hline Drugs of abuse & $\begin{array}{l}\text { Decrease cell proliferation and survival } \\
\text { in the SGZ }\end{array}$ & & Eisch et al. (2000), Crews et al. (2003) \\
\hline
\end{tabular}

synchronization and the strength required to change states (Roy et al., 2008).

This model postulates that states vary throughout time due to the individual behavior of each network, the interaction with other assemblies and threshold-based transitions (Krueger et al., 2008). Neuronal assemblies are quickly driven to sleep when individual neural networks enter in the sleep-like state. The strength of this response is proportional to the strength of the connections between individual neuronal assemblies. At the same time, if the circadian clock indicates that the body should be sleeping, the response of neuronal assemblies increases faster, triggering sleep. Experiments in silico suggest that neuronal over-stimulated assemblies will quickly enter in the sleep-like state, inducing surrounding neuronal assemblies to enter in the same state and leading to the whole-animal sleep. Thus, this model considers both the evolution of a global state of sleep and the emerging features of individual networks.

Sleep is currently seen as being imposed by the brain and regulated by an endogenous biological clock. However, this paradigm does not address many well-known phenomena of sleep, such as sleep inertia, restoring peak performance during sleep, homeostatic mechanisms of sleep, insomnia, somnolence or fatigue. The model of neuronal assemblies is more flexible, being easier to propose explanations for some sleep phenomena. For instance, sleep inertia may be a manifestation of some neuronal assemblies that remain in sleeplike state, after a sufficient number of neuronal assemblies are in wake-like state. In insomnia, some neuronal assemblies can be asleep, while others remain awake. The degree of sleepiness or the speed and accuracy of performance may be dependent on the fraction of neuronal assemblies that remain in wake-like state or sleep-like state. Brain imaging techniques evidenced that patients with insomnia display specific activation of wakefulness in some brain areas, while other areas have characteristics of sleep activity (Nofzinger et al., 2006).

To date, the model of neuronal assemblies does not provide answers on how many assemblies are needed to enter in a sleep-like state. However, similar limitations exist in the current paradigm of sleep regulation, which proposes a topdown imposition of sleep on the brain by regulatory circuits, not specifying which and how many areas need to be activated to induce sleep. Despite the insufficient understanding of the mechanisms of sleep, this model provides an evolutionary conceptual framework for further researches (Krueger et al., 2008). 


\section{Sleep Effects on Adult Neurogenesis}

\section{Seasonal Changes of Neurogenesis}

There is a correlation between sleep and neurogenesis across lifespan, since cell proliferation is maximal during early development stages, when daily amounts of sleep are higher. In addition, seasonal variability in neurogenesis and in sleep expression are associated in some species that migrate or hibernate (Mueller et al., 2013). In adult birds, for instance, neurogenesis and sleep patterns are noteworthy due to their marked variations in annual rates.

Tramontin and Brenowitz (2000) have shown that, in songbirds, the breeding season is anticipated by an increase in neuronal number, size and spacing in brain regions responsible for controlling song. According to the authors, this increase is related to seasonal changes in song production and learning and is induced by a vernal enhance in circulating sex steroids.

Claytona et al. (1997) analyzed the seasonal differences in hippocampal volume of two parasitic species of cowbirds $(M$. bonariensis and $M$. rufoaxillaris), reporting a decrease in the hippocampal volume during the non-breeding season in both species. They justified this decrease with seasonal changes in spatial memory demands. During the breeding season, an enlarged hippocampus is important for hosts' nests location. In contrast, during the non-breeding season, the lack of this demand is associated with a decrease in the relative hippocampal volume.

Barnea and Nottebohm (1994) injected adult black-capped chickadees with $\left[\mathrm{H}^{3}\right]$-thymidine and released and recaptured birds after 6 or more weeks. Newly formed neurons appeared in the hippocampus throughout the year, however, with a marked peak during the fall (October). This peak was halved in captive chickadees. Despite the addition of new neurons, they found no differences in the number of neurons along seasons. This evidence suggests that new neurons were born in different periods of the year, lived for few months, occurring, subsequently, neuronal loss. The authors hypothesized that new neurons added during the fall are part of an important process of new spatial memories acquisition, which is particularly important at this time of the year due to the food hoarding. They proposed that storing memories turned these neurons unviable for future processing, requiring them to be replaced.

Smulders et al. (2000) found similar results. They found a seasonal variation in hippocampal volume of black-capped chickadees in the fall, mainly associated to an increased number of neuronal and glial cells. Later, the number of neurons and glial cells decreased in parallel with the reduction of hoarding behavior. The authors suggested that this increase in the number of neurons and glial cells may provide a larger neural network to process information regarding more locations, a necessary ability to efficiently distribute food during the fall. They further suggested that this increase may be produced by seasonal signals inherent to the fall approximation, while its maintenance during hoarding season could be dependent of experience.

Studies with different species of birds found similar results: an increase in hippocampal volume during the fall, correlated with an increase of cell proliferation. This structural change appears to be associated with seasonal demands of spatial memory (Barnea and Nottebohm, 1994; Claytona et al., 1997; Smulders et al., 2000) and song production and learning (Tramontin and Brenowitz, 2000), in response to the breeding and hoarding seasons. Previous studies suggested that sleep plays, in birds, a crucial role on spatial memory and song learning processes (Gobes et al., 2010). Controversially, sleep is markedly reduced in the migratory season (spring and fall), when spatial memory and song learning processes are more acute. This reduction in amount of sleep during the migratory season does not affect memory and learning of birds. However, the same amount of reduction in sleep, experimentally provoked during the nonmigratory season (summer and winter), decreased the acquisition of components and the performance in a cognitive task (Gobes et al., 2010).

These set of studies suggest that sleep and neurogenesis are both essential to promote memory and learning, namely song learning and production. However, in birds, neurogenesis is higher when they sleep less. This negative correlation may be explained by the fact that short sleep deprivation (such as that seen in birds in the migratory season) can modulate the increase of neurogenesis, an effect verified in some experiments with rodents (Zucconi et al., 2006; Juneka et al., 2010), as will be discussed below. However, this positive effect of short sleep deprivation on neurogenesis of birds may only be seen in the migratory season due to the influence of other modulatory seasonal factors, such as sexual hormones.

Seasonal changes in hippocampal neurogenesis of rodents have been documented, however, no direct correlation with seasonal sleep patterns was established. Galea and McEwen (1999) observed higher rates of cell proliferation in adult female wild meadow voles (long-day breeders) captured during nonbreeding season. However, the authors attributed these seasonal fluctuation to hormone levels (since high levels of corticosterone and estradiol are negatively related with cell proliferation) and they related these evidences with changes in spatial learning. Ormerod and Galea (2003) acclimated laboratoryreared adult male meadow voles to short- or long-photoperiods, to induce non-breeding or breeding season, respectively. They found a similar density of BrdU-labeled cells in both reproductively active and inactive males. However, 5 weeks after, the density of labeled cells was elevated only in the reproductively active males, suggesting that reproductive status regulates the survival of new cells but not cell proliferation (Ormerod and Galea, 2003).

Sakamotoa et al. (2011) hypothesized that continuous adult neurogenesis is necessary to maintain and optimize innate olfactory responses, which is essential for social communication and predator avoidance (Walton et al., 2012), cues that vary seasonally (Heth et al., 1996). Walton et al. (2012) demonstrated an increased neurogenesis in the olfactory bulb of mice exposed to short-photoperiods for 10-15 weeks, comparatively to animals exposed to long-photoperiods, which they associated to changes in olfactory behavior.

Lavenex et al. (2000) examined adult neurogenesis in the dentate gyrus of wild eastern gray squirrels at three time points: in October, at the peak of the caching season; in January, 
when caching is complete but squirrels are still dependent on spatial memory to locate their caches; and in June, when squirrels are not actively engaged in further caching activity. Controversially, they demonstrated that cell proliferation and total neuron number are stable throughout the year, suggesting that other factors may modulate neurogenesis in this specie.

Structural and functional seasonal plasticity are essential properties of nervous system in several species inhabiting seasonal environments (Tramontin and Brenowitz, 2000). Despite the controversial results, neurogenesis appears to be seasonally influenced in some species, and this evidence may provide clues to the role of new generated neurons. To our knowledge, there is no evidence reporting a strict correlation between hibernation, sleep and neurogenesis, since seasonal variations in neurogenesis associated with seasonal variations in sleep have not been directly addressed. This association can be established in birds in an indirect way, due to their clear sleep and neurogenesis patterns during migratory and non-migratory seasons but, in rodents, there is no consensus. Seasonal neurogenesis patterns of rodents appear to be influenced by other factors, such as an enhanced in circulating sex steroids during the breeding season or enriched environments.

\section{The Role of Daily Rhythms on Adult Neurogenesis}

\section{Current Findings in Daily Changes of Neurogenesis}

Sleep is a circadian rhythm (Easton et al., 2004). If sleep plays a direct role in neurogenesis (Meerlo et al., 2009), it is conceivable to expect a rhythm in cell proliferation parallel to sleep-wake cycle.

There is substantial literature on the influence of daily rhythms in cell proliferation. In two studies, for instance, using male mice, it was observed that the number of proliferating cells in the SGZ is independent of the period of day. In the first study, BrdU was administered at six equally spaced periods, during $24 \mathrm{~h}$ of lightdark cycle. The number of BrdU-labeled cells, analyzed $2 \mathrm{~h}$ after the BrdU injections, showed no significant changes throughout light-dark cycle (Kochman et al., 2006). A second study, with the same procedure but using Ki-67 as a marker, found the same evidences (van der Borght et al., 2006). In an additional experiment of this study, the authors evaluated the effects of physical activity in the number of proliferating cells. They stimulated a group of mice with a running wheel for 9 days, while a control group were placed in a standard cage. After the experimental procedure, the animals were euthanized, before or after their active period (the night of circadian cycle). Cell proliferation was significantly stimulated by physical exercise, with a strongest effect after their active phase. This effect was not observed during their resting period. Collectively, the results of these two experiments suggest that hippocampal cell proliferation is coordinated with the behavioral activity but not with the circadian rhythm (van der Borght et al., 2006).
In order to analyze the association between circadian phase and exercise in neurogenesis, Holmes et al. (2004) allowed mice free access to a running wheel for 1,2 , or $3 \mathrm{~h}$ per day, in three different time points: middle of the light phase; beginning and middle of the dark phase. Running activity significantly promoted proliferation, survival, and newborn neurons in the mice with access to the running wheel for $3 \mathrm{~h}$ during the middle of the dark phase. This evidence proposes a modulation of both the circadian phase and the amount of exercise in the influence of physical activity on neurogenesis.

In a study with adult rats (Guzman-Marin et al., 2007b), two groups of animals were BrdU-injected four times: 2, 9, 14, or $21 \mathrm{~h}$ after de beginning of the light phase. Animals of the experimental group lived in a complex environment, while animals of the control group were placed in standard cages. Brains samples were collected $2 \mathrm{~h}$ post-injections. In both groups, regardless of their daily activity (regulated by the complexity of the environment of the cages), the animals injected $9 \mathrm{~h}$ after the beginning of the light phase showed a significant increase of BrdU-positive cells in the SGZ. These results evidenced a daily rhythm of cell proliferation, with a proliferation peak at the end of the light period, suggesting that cell proliferation may be enhanced by sleep and other variables associated with the light phase.

Tamai et al. (2008) explored daily variations in the division of neural progenitors in the SGZ and SVZ of adult mice. They found a clear day/night variation in M-phase cells, with a significant increase during the night. This increase was correlated with an increase of newborn neurons in the SGZ during the same period. However, they found no variation in the number of Sphase progenitors across the day-night cycle. In the SVZ, no variation in the number of $\mathrm{M}$-phase cells was found throughout the day-night cycle, suggesting that the influence of daily rhythms on cell proliferation may have a regional specificity (Tamai et al., 2008).

\section{The Controversial Data on Dentate Gyrus Neurogenesis Changes Along the Day}

Most experiments with rodents reject the hypothesis that cell proliferation in the SGZ has a significant daily rhythm. Studies with mice show that proliferating cell rate more dependent on daily exercise than on circadian rhythms (Holmes et al., 2004; Kochman et al., 2006; van der Borght et al., 2006). One study with rats points to a daily rhythm in cell proliferation, with a peak in the end of their sleep period, regardless of daily activity (Guzman-Marin et al., 2007b). It is unclear, from these set of results, whether this peak is dependent on sleep, circadian rhythms or daily exercise. Differences in genetic background between rats and mice may contribute to these controversial results.

Moreover, although the SGZ is the most significant region of cell proliferation, a small amount of proliferating cells was found in the hilus (Meerlo et al., 2009). Studies with mice, that found no daily rhythms in cell proliferation in the SGZ, reported higher levels of cell proliferation in the hilus during the sleep phase (Ishida et al., 2005; Kochman et al., 2006). It is thought that neurogenesis in the hilus generates more glial cells than 
neurons. Thus, these results suggest a circadian influence, possibly associated to sleep, in gliogenesis of mice (Meerlo et al., 2009).

\section{Potential Mechanisms: the Possible Influence of Hypothalamus-Pituitary-Adrenal Axis}

It has been proposed that the influence of daily rhythms on cell proliferation rate is modulated by adrenal steroid levels, which are regulated by the activation of the HPA axis (Cameron and McKay, 2001).

The HPA axis is the greatest part of the neuroendocrine system and controls several body processes. Its complex set of direct influences and feedback interactions includes the paraventricular nucleus (PVN) of the hypothalamus. The PVN has neuroendocrine neurons responsible for synthesizing and releasing vasopressin and corticotropin-releasing hormone (CRH). These two hormones regulate the anterior lobe of the pituitary gland, stimulating the secretion of adrenocorticotropic hormone (ACTH). The ACTH stimulates the adrenal cortex to synthesize and release glucocorticoid hormones (mainly cortisol in humans), which act in a negative feedback cycle on the hypothalamus and pituitary gland. The CRH secretion can be influenced by stress, physical activity, illness, sleep/wake cycle and circadian rhythm (Cameron and McKay, 2001).

The activity of the HPA axis has marked circadian effects (Ishida et al., 2005). Circadian rhythms influence cortisol secretion, through the connections between the PVN and SCN. In humans, cortisol levels reach their lowest point at midnight, starting to rise $\sim 2-3 \mathrm{~h}$ after and reaching its peak around 9 am, induced by light (Buckley and Schatzberg, 2005). The increase of glucocorticoid levels may induce a decrease in the basal rate of cell proliferation during the light phase, similarly to what happens, for instance, in the presence of stressor factors. In response to stress, the HPA axis promotes the secretion of adrenal steroids (Fuchs and Gould, 2000; Duman et al., 2001), that are negatively correlated with the hippocampal neurogenesis (Cameron and McKay, 2001). Thus, if cortisol reaches its lowest level during sleep, it is expected an increase in cell proliferation at this phase.

\section{Sleep Deprivation Studies}

\section{Different Levels of Sleep Deprivation}

Sleep disruption induces psychological and neurobiological changes (Goel et al., 2009), and affects a range of cognitive domains such as attention and working memory (Diekelmann and Born, 2010). To determine the role of sleep deprivation on neurogenesis, several studies used experimental paradigms to interrupt sleep of rodents for different periods of time. In experiences of total or partial sleep deprivation, wakefulness is forced through a variety of methods, such as soft handling, forced locomotion in a slowly rotating wheel or by placing rats on water-covered platforms. Effects unrelated to sleep loss (as exercise and/or stress) were controlled by the inclusion of additional groups or experimental conditions (Table 2).

\section{Proliferation and Survival of New Neurons in Prolonged Sleep Deprivation}

Sleep has been hypothesized as a facilitator of adult hippocampal neurogenesis, since prolonged sleep deprivation of adult rodents has a negative impact on cell proliferation, survival, maturation and differentiation of new neurons in the SGZ (Mirescu et al., 2006). However, short sleep deprivation (lesser than $24 \mathrm{~h}$ ) seems to not affect neurogenesis (Roman et al., 2005; Mirescu et al., 2006; Guzman-Marin et al., 2007a).

The effects of prolonged sleep deprivation on cell proliferation rate vary between studies and can be persistent. Tung et al. (2005) sleep-deprived two groups of adult male Sprague-Dawley rats for $48 \mathrm{~h}$, using a disk-over-water paradigm. After, one group was allowed to sleep for $8 \mathrm{~h}$, while the other group had an additional sleep deprivation period for $8 \mathrm{~h}$. A control group was not sleep-deprived. After, animals were BrdU-injected and brain samples were collected $2 \mathrm{~h}$ later. The dentate gyrus of rats sleepdeprived for $56 \mathrm{~h}$ showed a reduction on cell proliferation of $36 \%$, comparatively to animals of the control group. A similar reduction (of 39\%) was observed in rats allowed to a sleep recovery for $8 \mathrm{~h}$, demonstrating that the suppressive effects of prolonged sleep deprivation on cell proliferation are maintained after a sleep recovery for $8 \mathrm{~h}$.

Mirescu et al. (2006) found similar evidences with adult male Sprague-Dawley rats. They examined the effects of acute $(24 \mathrm{~h})$ and prolonged $(72 \mathrm{~h}$ ) sleep deprivation on cell proliferation on the granule cell layer, marking proliferating cells with BrdU. Two hours after the injections, the number of BrdU-labeled cells of animals acute sleep-deprived did not differ from undisturbed animals. However, BrdU-labeled cells were significantly reduced in animals submitted to a prolonged sleep deprivation. This reduction remained 1 week after the injections as well as 3 weeks after, when BrdU-labeled cells should express mature neuronal nuclei.

Mice with 6-8 weeks old were sleep-deprived for 10-12 h, starting at the beginning of their sleep period. Mice of the control group were undisturbed. After sleep deprivation, corticosterone levels in plasma were similar to control mice, suggesting that the animals of the experimental group were not stressed. Mice were BrdU-injected and, $2 \mathrm{~h}$ later, they were euthanized. As result, the number of BrdU-labeled cells was no altered, confirming the hypothesis that the basal rate of cell proliferation in the SGZ is not affected by short sleep restriction (van der Borght et al., 2006).

In an experiment by Guzmán-Marín et al. (2003), male rats were divided into three groups: the treadmill sleep-deprived group, which was kept awake for $96 \mathrm{~h}$ on a moving treadmill for $3 \mathrm{~s}$ on/12 s off; the treadmill control group, which was kept awake for $96 \mathrm{~h}$ on a moving treadmill for $15 \mathrm{~min}$ on/60 min off; and the control group, which was undisturbed. In the first two groups, the treadmill moved the same amount of time, but it allowed sustained periods of rest to the second group. BrdU was injected $48 \mathrm{~h}$ after the end of the experimental procedure. As result, the number of BrdU-labeled cells in the dentate gyrus 


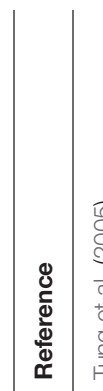

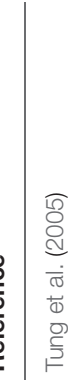

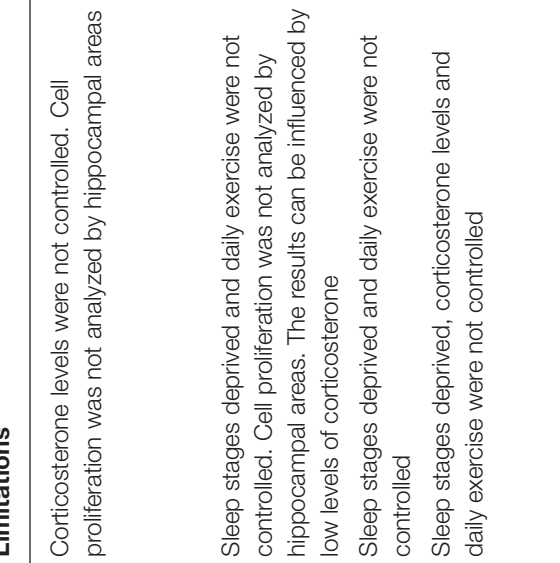

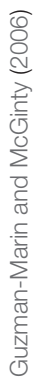

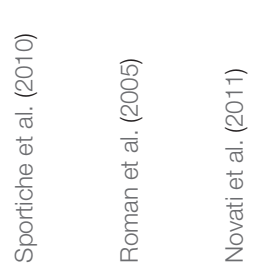

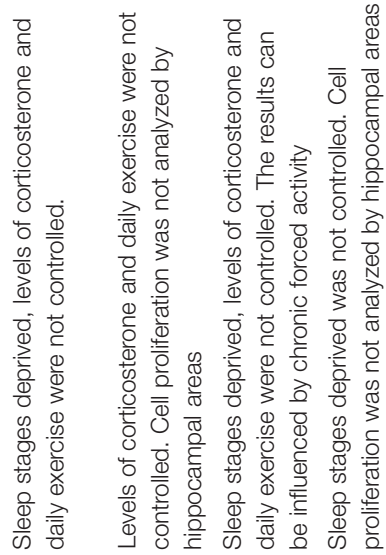

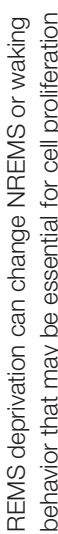

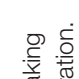

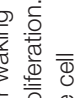
ì 茫京

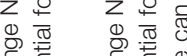

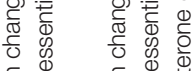

厄ٓ

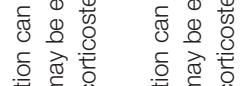

을 을

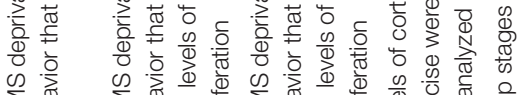

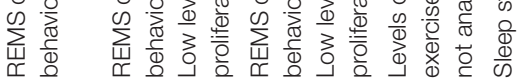

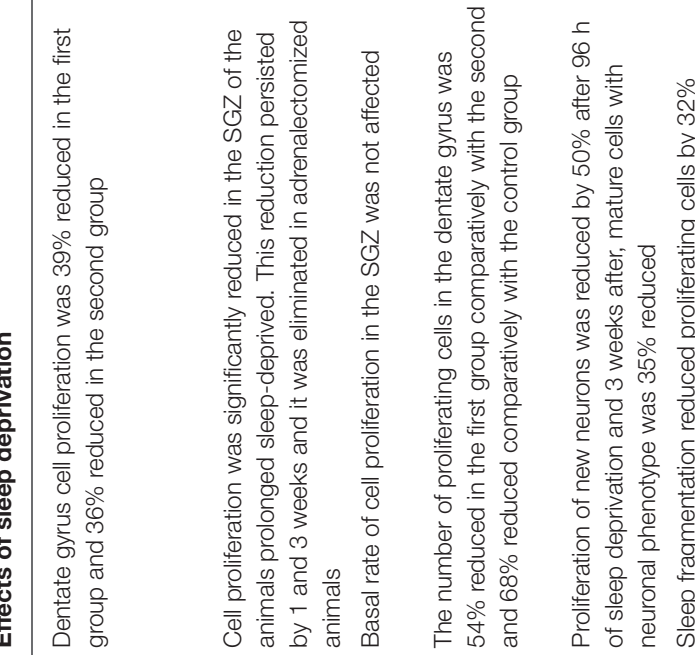

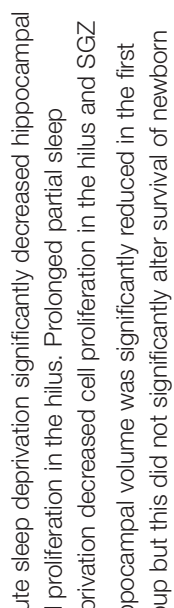

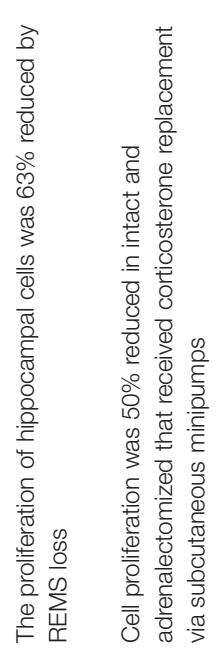

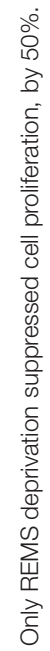

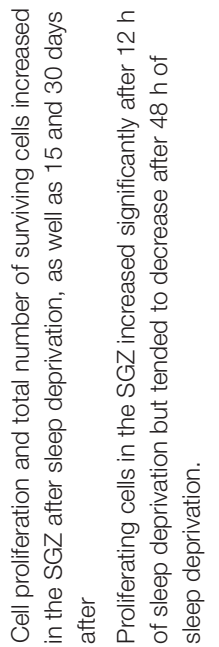

迹

萧市就

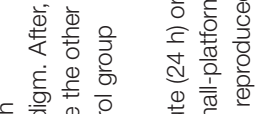

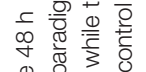

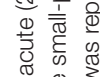

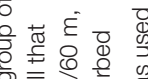

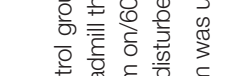

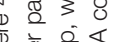

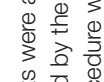

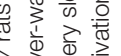

贾

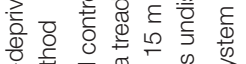

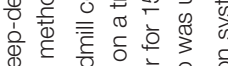

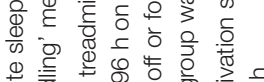

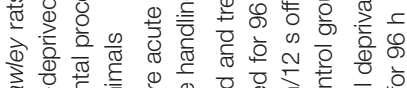

ब

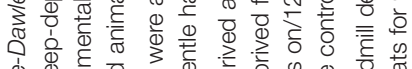

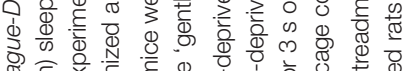

矛至 $\frac{1}{\infty}$

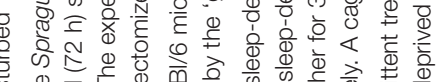

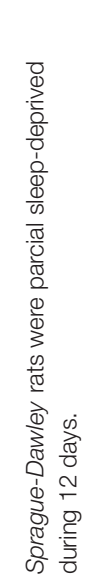

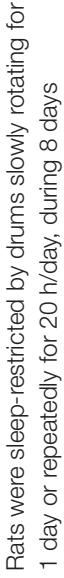

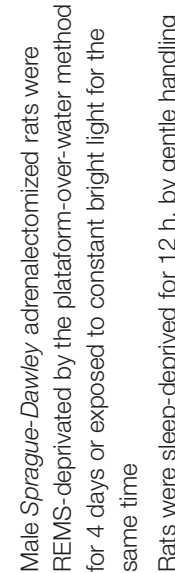

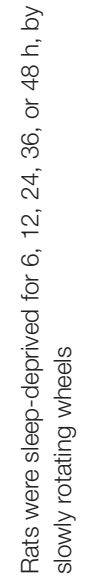


was $54 \%$ reduced in the first group, comparatively to the second group, and $68 \%$ reduced comparatively to the control group. Later, Guzman-Marin and McGinty (2006) used an intermittent treadmill deprivation system to sleep-deprived rats for $96 \mathrm{~h}$. BrdU and neuron-specific nuclear antigen (NeuN) were used as markers to quantify proliferative and neurogenic processes, respectively. Cell proliferation was $50 \%$ reduced after $96 \mathrm{~h}$ of sleep deprivation. Three weeks after, cells with a mature neuronal phenotype were $35 \%$ reduced.

The suppression of neurogenesis by sustained sleep fragmentation has been proposed to alter cognitive functions supported by the hippocampus (Sportiche et al., 2010). These effects were furthermore predicted to persist for the same time window of the functional maturation of new neurons. To test this hypothesis, male Sprague-Dawley rats were sleep-fragmented for 12 days by a treadmill and compared with sleep-fragmented control group. A treadmill control group was used to evaluate whether the physical activity, alone, would affect neurogenesis. Animals of these group were placed in an identical treadmill for 12 days, which was activated during equal periods of time but only in the waking phase. A cage control group was undisturbed. Animals were injected with BrdU on day 4 and 5 after the beginning of the experimental procedure, and returned to their cages for 14 days. Thereafter, to assess cognitive performance, animals were stimulated for 5 days with a Barnes maze with a constante escape tunnel position and 2 days with a rotated escape tunnel. Then, animals were sacrificed and their samples of dentate gyrus were collected and immunolabeled for BrdU and NeuN. Sleep fragmentation reduced BrdU-labeled cells by $32 \%$ in the sleep fragmentation group, comparatively to the sleep fragmentation and the treadmill control groups. In the cognitive assessment, animals of the sleep fragmentation group demonstrated a gradual reduced in escape time, but slower than animals of the other groups. Their most used search strategy was non-spatial and random, which persisted 2 weeks after the end of the experimental procedure (Sportiche et al., 2010).

In humans, Neylan et al. (2010) determined whether insomnia severity was associated with a decrease in the volume of the hippocampal dentate gyrus. With imaging techniques, they compared the volume of hippocampal subfields of veteran agematched men positive and negative for posttraumatic stress disorder diagnosis. Quality of sleep was assessed by the Insomnia Severity Index. As a result, higher scores on this test, indicative of worse insomnia, were correlated with reduced dentate subfields. These findings revealed an association between chronic sleep disruption and diminished volume of hippocampal subfields, suggesting a decreased neurogenesis and dendritic branching.

The effects of sleep deprivation on neurogenesis of the dentate gyrus are contradictory, including results that report a lack of specificity in antineurogenic effects of sleep loss.

Roman et al. (2005) observed the effects of sleep deprivation in different stages of hippocampal neurogenesis of rats. They sleep-deprived animals for 1 day or for $20 \mathrm{~h}$ per day, during 8 days, using slowly rotating drums. Addictionaly to a cage control group, a fourth group was composed, in which rats were forced to walk at double speed for half of the time, walking the same distance but being allowed to sleep. As a result, rats sleepdeprived for 1 day demonstrated a decreased cell proliferation in the hilus of the dentate gyrus. Repeated partial sleep restrition decreased cell proliferation both in the hilus and SGZ. However, a similar result was found in the fourth group, which might mean that this decrease was not a specific effect of sleep loss. In order to examine neuronal survival and differentiation, animals were injected with BrdU, NeuN and GFAP, a glial cell marker. Sleep restriction did not significantly affect the number of surviving BrdU-positive cells, as well as differentiated NeuN-positive and GFAP-positive cells. In conclusion, both prolonged or repeated partial sleep deprivation have negative effects on cell proliferation, mainly in the hilus, suggesting that sleep deprivarion may mostly decrease hippocampal gliogenesis. However, sleep deprivation did not appear to significantly affect the survival and differentiation of newborn cells.

Novati et al. (2011) divided adolescent male rats (30-61 postnatal days) in three groups: the chronic sleep restriction group, the forced activity control group, and the undisturbed control group. In the first group, rats were stimulated by a slowly rotating drum for $20 \mathrm{~h}$ and were allowed to sleep for $4 \mathrm{~h}$ per day, at the onset of their rest period. Animals of the second group were placed in a similar drum, which rotate at double of the speed for half of the time during the last $10 \mathrm{~h}$ of the dark phase, being allowed to sleep normally. After 1 and 4 weeks of sleep restriction, anxiety was assessed by an open field and elevated plus maze test, anhedonia was assessed by saccharin preference and HPA axis activity was evaluated. By the end of the experimental procedure, the hippocampal volume and neurogenesis were measured. Although the lack of behavioral changes, the hippocampal volume of the animals chronic sleep-deprived was significantly reduced 1 week after the experience. However, 4 weeks after the experience, this volume reduction was not reflected in changes in the survival of newborn cells, marked with BrdU, or in changes in the number of new neurons, marked with DCX. These results are not explained by high levels of corticosteroids, since the plasma levels of ACTH and corticosterone in the chronic sleep restriction group were low, and similar to other animals. Thus, these results indicate that insufficient sleep may cause reductions of hippocampal volume, however, independently of the HPA activity or neurogenesis.

\section{REM Sleep and NREM Sleep Deprivation}

There is evidence that a reduction in cell proliferation is associated with REMS restriction, while a decrease in the differentiation of adult neurons may be associated with restrictions in both NREMS and REMS (Meerlo et al., 2009). In most studies with rodents, sleep deprivation affects indistinguishably NREMS and REMS, and only few methods cause a specific reduction in REMS (Mueller et al., 2008).

One study selectively suppressed REMS on male SpragueDawley rats for 4 days, waking animals with a treadmill only when they entered in this stage (Guzman-Marin et al., 2008). Animals of a second group received the same stimulus, randomly during REMS or NREMS. NREMS and slow wave sleep, the third stage of NREMS, did not differ significantly between these two 
groups. Animals of a cage control groups were maintained undisturbed. The hippocampal proliferating cells were $63 \%$ reduced in animals REMS-deprived, comparatively to animals of the second group and $82 \%$ reduced, comparatively to cage controls. However, cell proliferation was also $51 \%$ reduced in the second, group comparatively to controls.

In a similar experience, Mueller et al. (2008) REMS-deprived intact and adrenalectomized male rats for $96 \mathrm{~h}$, using multiple and single-platform methods. In intact rats, proliferating cells of the dentate gyrus, marked with BrdU and Ki67, were $50 \%$ reduced, comparatively to undisturbed controls. This effect was observed in adrenalectomized rats that received continuous low-dose of corticosterone replacement via subcutaneous minipumps, but supressed in animals that received this replacement via drink water. In this group, corticosterone intake was $60 \%$ reduced, suggesting that low doses of corticosterone may upregulate cell proliferation, inhibiting the effects of sleep loss. Electroencephalogram records show that, with REMS deprivation, REMS was reduced by $95 \%$, while NREMS was $40 \%$ reduced and slow wave sleep was reduced by $45 \%$. This suggest that, although REMS deprivation methodology was efficient, it also partially suppressed NREMS and slow wave sleep. Later, Mueller et al. (2011) REMS-deprived adrenalectomized male SpragueDawley rats for 4 days. Other group of animals was stimulated with a constant bright light for the same time, attenuating or eliminating their daily rhythms but not affecting daily periods of REMS. Proliferating cells of the dentate gyrus, marked with BrdU, were $50 \%$ reduced by the REMS deprivation, and not affected by the constant bright light stimulation. NREMS and slow wave sleep did not differ significantly between groups. These results suggest an antineurogenic effect of REMS deprivation, and suport the hypothesis that hippocampal cell proliferation and survival may be independent of circadian rhythms (Mueller et al., 2011).

This set of results suggests that the decrease in hippocampal cell proliferation may be associated with a decrease in REMS, but does not exclude the role of NREMS and slow wave sleep. The experiment of Mueller et al. (2008) raises the the hypothesis that the disruption of NREMS and slow wave sleep or the disruption of interactions between REMS and NREMS may modulate the suppression of cell proliferation. On the other hand, the disruption of REMS may change NREMS and waking behavior, which may be essential for a normal cell proliferation. Thus, the role of NREMS on neurogenesis cannot be determined without selective deprive NREMS or slow wave sleep, which has methodological limitations due to the difficulties to sustain normal levels of REMS after NREMS deprivation.

\section{The Controversy: Acute Sleep Deprivation Enhance Neurogenesis}

Short sleep deprivation has little negative effects on basal rates of cell proliferation and survival. Zucconi et al. (2006) sleepdeprived adult rats for $12 \mathrm{~h}$, during their period of rest. Rats were BrdU-injected $4 \mathrm{~h}$ before and $2 \mathrm{~h}$ after sleep deprivation, and sacrificed at that moment, 15 or 30 days later. The results showed that $12 \mathrm{~h}$ of sleep deprivation significantly increased cell proliferation and survival in the dentate gyrus immediately after sleep deprivation, as well as 15 and 30 days later, comparatively with non-sleep-deprived animals. No changes were found in the SVZ, indicating that short sleep deprivation may be selectively related to hippocampal neurogenic signals.

Juneka et al. (2010) observed the effects of different periods of sleep deprivation on cell proliferation in the SGZ of adult rats. Animals were sleep-deprived for 6, 12, 24, 36, or $48 \mathrm{~h}$ and BrdU was administered $2 \mathrm{~h}$ before the end of sleep deprivation. The number of BrdU-labeled cells increased significantly after $12 \mathrm{~h}$ of sleep deprivation, and decreased after $48 \mathrm{~h}$ of sleep deprivation, comparatively to non-sleep-deprived controls. Proliferating cells were marked with Ki-67 or with proliferating cell nuclear antigen (PCNA). Sleep deprivation for $12 \mathrm{~h}$ did not alter immunolabeling for Ki-67, as well as PCNA and corticosterone levels. Immunoreactivity for Ki-67 and PCNA can mark cells in all phases of the cell cycle of the hippocampus of rats $(\sim 25 \mathrm{~h})$, while BrdU only labels cells in S-phase $(\sim 9.5 \mathrm{~h})$. These contradictory results indicate that $12 \mathrm{~h}$ of sleep deprivation might have affected the dynamics of the cell cycle. To test this hypothesis, rats of a different group were BrdU-injected $10 \mathrm{~h}$ before the end of $12 \mathrm{~h}$ of sleep deprivation. The results point to an acceleration of cell division of hippocampal progenitors, suggesting that short sleep deprivation increase the production of hippocampal progenitor cells by temporarily accelerating the cell cycle.

\section{Potential Mechanism}

The underlying mechanisms of the negative effects of sleep deprivation on different stages of adult neurogenesis are unknown. It has been hypothesized that these effects can be indirectly mediated by stress and their hormones, particularly by glucocorticoids. For instance, sleep deprivation of rats, with the small-platform method, significantly increased their leves of corticosterone and significantly decreased their cell proliferation. This experiment was replicated in adrenalectomized mice, which produce low levels of corticosterone, and the decrease of cell proliferation in the dentate gyrus was completely eliminated (Mirescu et al., 2006).

These results are controversial and contrast with recent studies described above, in which antineurogenic effects of sleep deprivation on the hippocampus were maintained with low levels of corticosterone (van der Borght et al., 2006; Guzman-Marin et al., 2008; Mueller et al., 2008; Novati et al., 2011). Furthermore, while high levels of corticosterone suppress cell proliferation, low levels of corticosterone promote cell proliferation (Cameron and Gould, 1994).

Adult neurogenesis is regulated by several molecular factors, including trophic factors, cytokines, hormones and neurotransmitters (Cameron and McKay, 2001; Kempermann, 2002). Many of these factors are affected by sleep deprivation and this may provide a link between insufficient sleep and reduced hippocampal neurogenesis. For instance, serotonin stimulate hippocampal neurogenesis due to the serotonin-1A receptor action (Radley and Jacobs, 2002; Banasr et al., 2004). Serotonergic activity is relatively low during sleep, which may not explain the suppressive effect of sleep deprivation in neurogenesis. However, this 
lower serotonergic activity during sleep may be necessary for the normal serotoninergic activity during wakefulness and, consequently, it may be important for a waking experience effects in neurogenesis. In rats, chronic sleep deprivation cause a reduction in the sensitivity of the serotonin-1A receptor system (Novati et al., 2008), which is not evident in short sleep deprivation. Similarly, several evidences suggest that short sleep deprivation does not appear to affect cell proliferation, while chronic sleep deprivation decrease cell proliferation in the hippocampus.

Insulin-like growth factor (IGF)-1 is one of several growth factors known as neurogenesis promoters (Trejo et al., 2001). Prolonged sleep deprivation in rats showed lower IGF-1 binding (Everson and Crowley, 2004). The Brain-derived neurotrophic factor (BDNF) also facilitates hippocampal neurogenesis (Scharfman et al., 2005; Guzman-Marin et al., 2006). The hippocampal expression of BDNF was decreased after 8 and $48 \mathrm{~h}$ of sleep deprivation (Guzman-Marin et al., 2006). This decrease is associated with REMS suppression, what may be an important evidence, given the association between the suppression of hippocampal cell proliferation and REMS loss (Guzman-Marin et al., 2008).

Growth hormone $(\mathrm{GH})$ could also be related with neurogenesis regulation. A recent study showed that $\mathrm{GH}$ administration strongly promotes adult cell proliferation in the dentate gyrus of rats, and protects the hippocampal neuronal precursors of the negative effects of chronic sleep deprivation (Irwin et al., 2006; García-García et al., 2011). The protective role of GH could have clinical relevance, since $\mathrm{GH}$ replacement therapy appears to improve both mood and sleep quality (Mahajan et al., 2004; Haack et al., 2007), effects that might be related to the neurogenesis in the hippocampus.
A decrease of cell proliferation after sleep deprivation can be associated to enhanced levels of pro-inflammatory cytokines, interleukin (IL)-6 and tumor necrosis factor (TNF-a). There are evidences that both IL-6 and TNF-a are increased after chronic sleep deprivation (Irwin et al., 2006; Haack et al., 2007), and IL6 plasma levels are enhanced in patients with insomnia (Burgos et al., 2006). In vitro, exposure to IL-6 and TNF-a diminishes cell proliferation and, in vivo, they can modulate the damaging effects of neuroinflammation in hippocampal neurogenesis (Monje et al., 2003).

The mechanism by which prolonged sleep deprivation affects adult neurogenesis may imply a complex group of interacting factors (Figure 1), which may, in fact, affect selectively different stages of neurogenesis process (Meerlo et al., 2009).

\section{Can Sleep Deprivation Affect Neurogenesis in SVZ, or Other Adult Neurogenic Areas?}

Most studies on the association between adult neurogenesis and sleep were focused on the dentate gyrus, excluding the SVZ. This can be explain by a greater interest in the hippocampus than in the olfactory bulb, the area to where migrate the majority of newborn cells generated in the SVZ (Meerlo et al., 2009).

Mirescu et al. (2006) studied the effects of 3 days of sleep deprivation in the SVZ and found no changes in cell proliferation, while it was significantly decreased in the SGZ, suggesting that effects of sleep deprivation may be regionally selective (Mirescu et al., 2006). Even within the dentate gyrus, some regional variations may be found. The effects of sleep deprivation appear

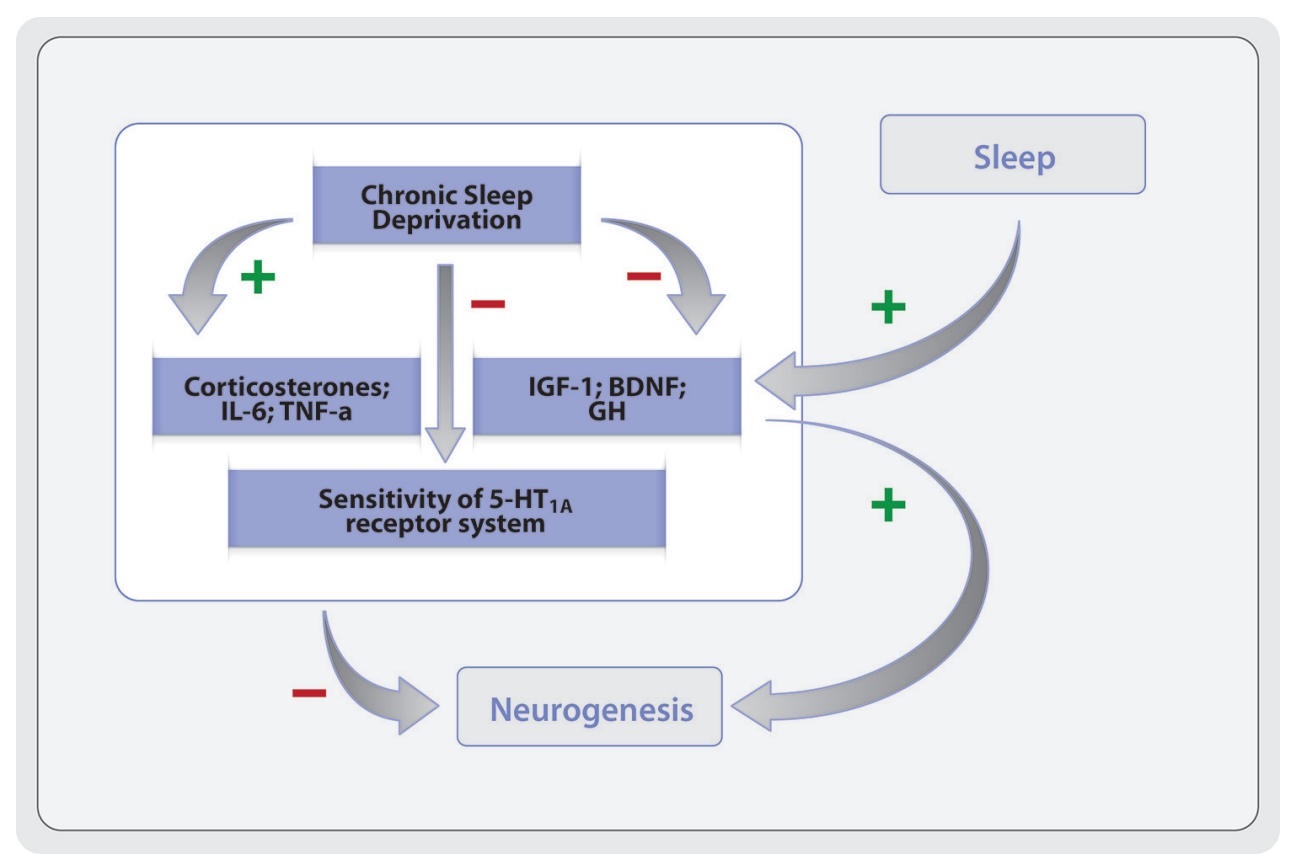

FIGURE 1 | Potential mechanisms of anti-neurogenic effects of chronic sleep deprivation. 
stronger in ventral than dorsal region of the dentate gyrus (Tung et al., 2005). It may be important to clarify these findings since different regions of the hippocampus have differente functions. Selective lesions in rodents revealed that the dorsal hippocampus seems to be responsible for certain forms of learning and memory, namely spatial learning, while the ventral hippocampus seems to be associated to regulation of emotional behavior (Moser and Moser, 1998).

\section{Other Interacting Aspects of Sleep and Neurogenesis}

Several studies have focused on the possible role of new neurons in the hippocampal functions, since hippocampus is the major component of cognitive-limbic system and important to cognition processes, like learning and memory (Moser and Moser, 1998). Additionally, the hippocampus establishes reciprocal connections with several brain areas, such as the amygdala and prefrontal cortex, which regulate the emotionality. It has been proposed that antineurogenic effects of sleep deprivation act as a mediating factor on cognitive and mood deficits (Jacobs et al., 2000; Sportiche et al., 2010).

\section{Learning and New Memory Formation}

Hippocampus-dependent learning and memory are associated with an increase of hippocampal neurogenesis (Dobrossy et al., 2003), while learning deficits are associated with a decrease (Leuner et al., 2006). In addition, several conditions that decrease cell proliferation on the dentate gyrus (such as acute and cronic stress, increased levels of circulating corticosteroids, aging and opiates) also damage the hippocampusdependent learning. Moreover, conditions that enhance hippocampal cell proliferation (such as increased environmental complexity, physical exercise, and estrogen levels) are associated with an increase in learning and new memories formation (Gross, 2000). Finally, experimental tasks that stimulate hippocampal-dependent learning seem to contribute to a longer survival of newborn neurons in the hippocampal dentate gyrus (Gould et al., 1999).

Sleep appears to play a role in learning and new memories formation, and its deprivation disrupts these two cognitive functions. This evidence suggests that sleep may support learning and memory by promoting survival, maturation and functional integration of new hippocampal neurons, under an unexplored mechanism (Meerlo et al., 2009).

A study with rats examined if the effects of sleep deprivation on hippocampal-dependent learning was related to a decrease in the survival of new cells. Two groups of animals were stimulated in a water maze for 4 days, in a hippocampal-dependent spatial task (a submerged and invisible platform) or in a nonhippocampal-dependent spatial task (a visible platform). After each training day, on group of animals were kept awake for the first $6 \mathrm{~h}$ of its normal rest time. Animals were BrdUinjected 1 week before the beginning of the training. During the experience, the generated cells a week before the training should be mature and incorporated in the hippocampal network. Rats trained on hippocampal-dependent spatial task had a pronounced increase of newborn cells survival. However, this effect was suppressed in animals submitted to the same task but sleep-deprived. In the sleep-deprived group spatial learning was impaired but, surprisingly, non-spatial learning was improved. In both groups, fully rested animals applied a spatial strategy in both tasks, which interfered with the performance in the non-spatial task. In sleep-restricted group, this spatial strategy was eliminated, and animals used only nonspatial information, improving non-spatial performance. These findings suggest that sleep loss altered behavioral strategies and reversed neurogenic effects of hippocampus-dependent learning (Hairston et al., 2005)

In humans, imaging studies have confirmed the role of sleep in the hippocampal functions, particularly in learning and memory (Peigneux et al., 2004; Orban et al., 2006). In addition, the cognitive performance in patients with chronic insomnia is disturbed (Backhaus et al., 2006; Nissen et al., 2006) and imaging techniques of these patients showed a significant reduction in hippocampal volume (Riemann et al., 2007). Reduced adult neurogenesis in humans, caused by sleep disturbance, may be a limited explanation to justify this decreased volume, but may contribute to this phenomenon (Meerlo et al., 2009).

According to some models, new memories are formed due to a structural remodeling of existing synapses and due to an adaptation of the synaptic strength in the existing circuits. Sleep, after the initial learning, appears to contribute to this process through the neural repetition and reactivation of neural plasticity process (Graves et al., 2001; Stickgold, 2005; Stickgold and Walker, 2005). This synaptic plasticity dependent of sleep can involve both the existing neurons and the maturation and strengthening of synapses of new neurons.

\section{Mood Regulation}

Recent evidences showed that hippocampal neurogenesis is reduced in animal models of depression. Furthermore, antidepressant treatment promotes neurogenesis (Zucconi et al., 2006). This raises the hypothesis that changes in the hippocampal neurogenesis may mediate emotional and cognitive deficits observed in mood disorders (Jacobs et al., 2000; Sahay and Hen, 2007).

Sleep disruption has been associated with mood regulation deficits, however, by an unknown mechanisms. In has been hypothesized that chronic sleep deprivation contributes to the etiology of depression by inhibits cell proliferation and hippocampal neurogenesis. Studies with rodents have shown that prolonged sleep deprivation progressively leads to physiological and neurobiological modifications similar to those experienced in patients with major depressive disorder (MDD; Meerlo et al., 2009).

\section{Pharmacology Perspective: Hypnotic Drugs and Neurogenesis}

Sleep deprivation appears to suppress neurogenesis. Thus, it would be conceivable that hypnotic drugs, by improve the quality of sleep, could have a neurogenic effect. To test this hypothesis, 
Takase et al. (2009) administered Zolpidem (5, 10, or $20 \mathrm{mg} / \mathrm{kg}$ ), a non-benzodiazepine hypnotic drug, in young and old male Sprague-Dawley rats (Table 3). Zolpidem was ingested twice daily, at the onset and at the middle of the rest phase, for 2 days (acute administration) or 21 days (chronic administration). Acute ingestion significantly suppressed cell proliferation in the aged animals. In both groups, cell proliferation supression was higher in the hilus than in the SGZ. The lower dose of Zolpidem reduced neurogenesis by $25 \%$ in the dentate gyrus of young animals and the higher dose had no significative effects. The authors argued that the chronic administration of hypnotic drugs in young animals may cause a disruption of normal sleep, which may be related to a reduction in cell survival. In aged animals, the low dose increased cell survival in the SGZ by $11 \%$ and decrease cell survival in the hilus by $6 \%$. In aged animals, hypnotic drugs may improve the speel quality (typically disturbed at this age), causing a benefical effects on neurogenesis. However, even in aged group, chronic ingestion of Zolpidem had little or no effect on cell proliferation in both groups of rats, suggesting little benefic effects of hypnotic drugs on neurogenesis (Takase et al., 2009).

Psychostimulant drugs, such as Modafinil or caffeine, administered in rats sleep-deprived for 2 days, prevents the decrease of proliferating and differentiating cells, marked with BrdU and DCX, respectively (Sahu et al., 2013), opposing to the suppressive effects of the sleep deprivation in the cell proliferation and differentiation.

A major finding in the pharmacological perspective of neurogenesis was the discovery that antidepressant drugs increases hippocampal neurogenesis (Table 3). Thus, stimulating adult hippocampal neurogenesis may be a new drug target or mechanism of antidepressants, to reach its therapeutic effects (Takase et al., 2009).

Several studies had been demonstrating the stimulating effects of multiple classes of antidepressants on hippocampal neurogenesis in a chronic, but not acute, time course (Boldrini et al., 2009). A set of studies demonstrated that chronic antidepressant treatment can upregulate the expression of BDNF in the hippocampus (Nibuya et al., 1995), which seems to stimulate adult cell proliferation, differentiation and survival in vitro and in vivo
(Takahashi et al., 1998). Addictionaly, chronic antidepressant treatment can oppose to the downregulation of the hippocampal BDNF expression caused by stress (Nibuya et al., 1995).

In a study of Malberg et al. (2000) with adult male SpragueDawley rat, it was investigated the effect of different classes of antidepressants and electroconvulsive seizure treatment on hippocampal neurogenesis, using BrdU as a marker. Chronic treatment with electroconvulsive seizures increased the BrdUpositive cells in the dentate gyrus by $50 \%$, while chronic administration (14 or 28 days) of chemical antidepressants a monoamine oxidase inhibitor (MAOI); a selective serotonin reuptake inhibitors (SSRIs) and a tricyclic antidepressants (TCAs) - increased the BrdU-positive cells by $20-40 \%$ (Malberg et al., 2000). Acute administration (1 or 5 days) of a SSRI did not change the number of BrdU-positive cells, suggesting that chronic, but not acute, antidepressant treatment enhance BrdU-positive cells in the hippocampus, consistently with the time window of their therapeutic action (Duman et al., 1997).

To examine the specificity of the neurogenic effects of antidepressants on neurogenesis, the influence of Haloperidol, a nonantidepressant psychotropic drug, on neurogenesis was evaluated. As a result, chronic administration of Haloperidol did not significantly alter the number of BrdU-positive cells (Malberg et al., 2000).

Boldrini et al. (2009), using post mortem tissue samples, determined the anatomical location of neural progenitor cells with Nestin-IR and proliferating cells with Ki-67 in the dentate gyrus of non-psychiatric controls, untreated MMD patients, MDD patients treated with SSRIs or TCAs in the past 3 months before death. Patients treated with SSRIs and TCA evidenced a increase in neuronal progenitor cells than untreated MDD patients and controls. Dividing cells number were higher in MDD patients treated with TCAs than in untreated MDD patients, patients treated with SSRIs, and controls. Treated patients had a larger dentate gyrus volume, comparatively to untreated MDD patients or controls and this increase of neuronal progenitors and dividing cells was localized in the rostral dentate gyrus (Boldrini et al., 2009).

TABLE 3 | Effects of hypnotic and antidepressant drugs on neurogenesis.

\begin{tabular}{|c|c|c|}
\hline Drug & Effects on neurogenesis & Reference \\
\hline $\begin{array}{l}\text { Zolpidem (hypnotic drug) was administered in aged and } \\
\text { young adults rats twice daily, at the onset and middle of the } \\
\text { rest phase, for } 2 \text { days (acute study) or } 21 \text { days (chronic study) }\end{array}$ & $\begin{array}{l}\text { Acute administration produced a suppression on cell proliferation in the aged } \\
(30-40 \%) \text { and young adults (10-15\%), larger in the hilus than in the SGZ. } \\
\text { Chronic administration produced a small reduction of cell survival in the SGZ } \\
\text { of young animals and a slight increase in aged animals }\end{array}$ & Takase et al. (2009) \\
\hline $\begin{array}{l}\text { Modafinil or caffeine (psychostimulant drugs) were } \\
\text { administered in rats total sleep-deprived for } 2 \text { days }\end{array}$ & $\begin{array}{l}\text { Prevented decline in neuronal proliferation and differentiation after sleep } \\
\text { deprivation }\end{array}$ & Sahu et al. (2013) \\
\hline $\begin{array}{l}\text { Different classes of antidepressants (MAOI; SSRI; TCA) and } \\
\text { electroconvulsive seizure were tested in adult male } \\
\text { Sprague-Dawley rats }\end{array}$ & $\begin{array}{l}\text { Chronic administration of electroconvulsive seizures enhance proliferating } \\
\text { cells by } 50 \% \text {, while different classes of antidepressant increased proliferating } \\
\text { cells by } 20-40 \%\end{array}$ & Malberg et al. (2000) \\
\hline $\begin{array}{l}\text { A non-antidepressant psychotropic drug (Haloperidol) was } \\
\text { tested in adult male Sprague-Dawley rats }\end{array}$ & $\begin{array}{l}\text { Chronic administration did not significantly alter the number of BrdU-positive } \\
\text { cells }\end{array}$ & Malberg et al. (2000) \\
\hline $\begin{array}{l}\text { The number of cells in the dentate gyrus were compared } \\
\text { between postmortem non-psychiatric controls, untreated } \\
\text { MDD patients, and MDD patients treated with SSRIs or TCAs }\end{array}$ & $\begin{array}{l}\text { MDD treated patients had a increase in neuronal progenitors and a larger } \\
\text { dentate gyrus volume. Dividing cells were greater in MDD patients treated } \\
\text { with TCAs. The increase of neuronal progenitors and dividing cells was } \\
\text { localized on the rostral dentate gyrus. }\end{array}$ & Boldrini et al. (2009) \\
\hline
\end{tabular}


The neural mechanisms underlying the therapeutic effects of antidepressants still unknown, but the upregulation of growth factors and neurogenesis may be involved. Warner-Schmidt and Duman (2007) demonstrated that VEGF is an essential mediator of the neurogenic and behavioral actions of antidepressants, by two high-affinity receptor tyrosine kinases (Flk-1 and Flt-1). Male Sprague-Dawley rats were and treated with electroconvulsive seizures. Animals of the control group were handled identically, but received no shock. A SSRI, a TCA, or saline was injected once or twice daily. As result, VEGF was identified as a key mediator of the actions of two classes of antidepressants and it was induced by the SSRI, the TCA and by the electroconvulsive seizure, in a time window consistent with the time window of cell proliferation and maturation and the time window of the therapeutic action of antidepressants (Warner-Schmidt and Duman, 2007).

\section{Future Studies}

The current knowledge on adult neurogenesis comes from laboratory studies with animal models. However, adult neurogenesis has been demonstrated in humans (Eriksson et al., 1998), despite the methodological limitations of measure new generated neurons in live participants.

Recent developments of magnetic resonance imaging techniques are promising and opens the possibility to study neurogenesis in humans under several experimental conditions and to study of the association between different pathologies and neurogenesis (Shapiro et al., 2006; Manganas et al., 2007). Furthermore, imaging techniques could ultimately provide an opportunity to study the association between human sleep deprivation and neurogenesis, as well as it has been done in rodent models.

Considering all studies with animal models discussed throughout this review, there are several controversial and contradictory results. Results obtained with some species and under certain experimental conditions can not be replicated in other species, since neurogenesis and sleep regulation may be conditioned by the individual and genetic features of each specie. Thus, studies of neurogenesis with animal models need to be extended to produce more robust results on the underlying mechanisms of the modulatory effects of sleep on neurogenesis.

More studies are needed to determine the antineurogenic effects of sleep deprivation on different hippocampal areas, given the evidence of a functional differentiation of different hippocampal subfields. It is also necessary to explore the effects of sleep deprivation on neurogenesis of other brain areas, which could be useful to understanding the functional outcome of neurogenesis. The effects found in the basal rate of cell proliferation in the REMS versus NREM deprivation also need to be replicated to reach more robust conclusions.

\section{References}

Abrous, D. N., Koehl, M., and Le Moal, M. (2005). Adult neurogenesis: from precursors to network and physiology. Physiol. Rev. 85, 523-569. doi: 10.1152/physrev.00055.
The neurogenic link between sleep, learning, hippocampusdependent memory and mood disorders need to be clarified, and the functional relevance of increased neurogenesis caused by antidepressant treatments need to be explored with clinical studies in humans. It is necessary to understand if neurogenesis is related with a behavioral and molecular response to antidepressant treatments in MDD patients. Finally, the negative hypnotic effects of neurogenesis need to be clarified and tested in humans, since they can have unknown side effects in human adult neurogenesis, with repercussions to other cognitive and emotional functions.

\section{Conclusion}

The knowledge of neurogenesis in adult mammals has significantly progressed over the last decade (Arias-Carrión et al., 2007; Yuan and Arias-Carrion, 2011; Yuan et al., 2014). The decline of the belief that neuronal neurogenesis ends at puberty seems to be part of the recognition of the plasticity of adult brain and its structural modulation based on experience (Gross, 2000). It is now accepted that adult neurogenesis actively occurs throughout life in the SVZ and SGZ of the hippocampal dentate gyrus, appearing to be limited or absent in others areas of the CNS. However, after a pathologic stimulation, such as brain injury, neurogenesis may occur in non-neurogenic areas (Arias-Carrión et al., 2007; Yuan and Arias-Carrion, 2011).

While studies on adult human neurogenesis await the development of in vivo imaging techniques, data from animal models suggests that newly generated neurons in adulthood may be involved in hippocampal plasticity.

Chronic sleep disruption decreases adult neurogenesis in rodents. However, short sleep deprivation seems to enhance cell proliferation and survival. The chronic effects of sleep deprivation may impair the hippocampal integrity and may ultimately lead to cognitive dysfunction, contributing to the development of mood disorders and other pathologies. Whether adult neurogenesis plays a role in such modulation is yet to be determined. Targeting adult neurogenesis during sleep disorders might therefore to provide one interesting approach to reverse the potential disruption of chronic sleep disorders on cognitive and emotional function.

\section{Acknowledgment}

OA-C is supported by CONACYT-BMBF 2013 (Grant 208132).

Alvarez-Buylla, A., and Lim, D. A. (2004). For the long run: maintaining germinal niches in the adult brain. Neuron 41, 683-686. doi: 10.1016/S0896-6273(04) 00111-4

Arias-Carrión, O., Freundlieb, N., Oertel, W. H., and Höglinger, G. U. (2007). Adult neurogenesis and Parkinson's disease. CNS Neurol. Disord. Drug Targets 6, 326-335. doi: 10.2174/187152707783220875 
Arias-Carrión, O., Machado, S., Paes, F., Velasques, B., Teixeira, S., CardenasMorales, L., et al. (2011). Is rTMS an effective therapeutic strategy that can be used to treat Parkinson's disease? CNS Neurol. Disord. Drug Targets 10, 693-702. doi: 10.2174/187152711797247821

Backhaus, J., Junghanns, K., Born, J., Hohaus, K., Faasch, F., and Hohagen, F. (2006). Impaired declarative memory consolidation during sleep in patients with primary insomnia: influence of sleep architecture and nocturnal cortisol release. Biol. Psychiatry 60, 1324-1330. doi: 10.1016/j.biopsych.2006. 03.051

Banasr, M., Hery, M., Printemps, R., and Daszuta, A. (2004). Serotonin induced increases in adult cell proliferation and neurogenesis are mediated through different and common 5-HT receptor subtypes in the dentate gyrus and the subventricular. Neuropsychopharmacology 29, 450-460. doi: 10.1038 /sj.npp. 1300320

Barnea, A., and Nottebohm, F. (1994). Seasonal recruitment of hippocampal neurons in adult free-ranging black-capped chickadees. Proc. Natl. Acad. Sci. U.S.A. 91, 11217-111221. doi: 10.1073/pnas.91.23.11217

Belluzzi, O., Benedusi, M., Ackman, J., and LoTurco, J. J. (2003). Electrophysiological differentiation of new neurons in the olfactory bulb. J. Neurosci. 23, 10411-10418.

Boldrini, M., Underwood, M. D., Hen, R., Rosoklija, G. B., Dwork, A. J., Mann, J. J., et al. (2009). Antidepressants increase neural progenitor cells in the human hippocampus. Neuropsychopharmacology 34,2376-2389. doi: 10.1038/npp.2009.75

Bolteus, A. J., and Bordey, A. (2004). GABA release and uptake regulate neuronal precursor migration in the postnatal subventricular zone. J. Neurosci. 24, 7623-7631. doi: 10.1523/JNEUROSCI.1999-04.2004

Brown, J., Cooper-Kuhn, C. M., Kempermann, G., Praag, H. V., Winkler, J., Gage, F. H., et al. (2003). Enriched environment and physical activity stimulate hippocampal but not olfactory bulb neurogenesis. Eur. J. Neurosci. 17, 2041-2046. doi: 10.1046/j.1460-9568.2003.02647.x

Buckley, T. M., and Schatzberg, A. F. (2005). Review: on the interactions of the hypothalamic pituitary-adrenal (HPA) axis and sleep: normal HPA axis activity and circadian rhythm, exemplary sleep disorders. J. Clin. Endocrinol. Metab. 90 3106-3114. doi: 10.1210/jc.2004-1056

Burgos, I., Richter, L., Klein, T., Fiebich, B., Feige, B., Lieb, K., et al. (2006) Increased nocturnal interleukin-6 excretion in patients with primary insomnia: a pilot study. Brain Behav. Immun. 20, 246-253. doi: 10.1016/j.bbi.2005.06.007

Cameron, A. H., and McKay, R. D. (2001). Adult neurogenesis produces a large pool of new granule cells in the dentate gyrus. J. Comp. Neurol. 435, 406-417. doi: $10.1002 /$ cne. 1040

Cameron, H. A., and Gould, E. (1994). Adult neurogenesis is regulated by adrenal steroids in the dentate gyrus. Neuroscience 61, 203-209. doi: 10.1016/03064522(94)90224-0

Cao, L., Jiao, X., Zuzga, D. S., Liu, Y., Fong, D. M., Young, D., et al. (2004). VEGF links hippocampal activity with neurogenesis, learning and memory. Nat. Genet. 36, 827-835. doi: 10.1038/ng1395

Cheng, M., Bullock, C. M., Li, C., Lee, A. G., Bermak, J. C., Belluzzi, J., et al. (2002). Prokineticin 2 transmits the behavioural circadian rhythm of the suprachiasmatic nucleus. Nature 417, 405-410. doi: 10.1038/417405a

Claytona, N. S., Reboredab, J. C., and Kacelnikc, A. (1997). Seasonal changes of hippocampus volume in parasitic cowbirds. Behav. Processes 41, 237-243. doi: 10.1016/S0376-6357(97)00050-8

Conover, J. C., Doetsch, F., Garcia-Verdugo, J., and Gale, N. W. (2000). Disruption of Eph/ephrin signaling affects migration and proliferation in the adult subventricular zone. Nat. Neurosci. 3, 1091-1097. doi: 10.1038/80606

Crews, F. T., Miller, M. W., Ma, W., Nixon, K., Zawada, W. M., and Zakhari, S. (2003). Neural stem cells and alcohol. Alcohol. Clin. Exp. Res. 27, 324-335. doi: 10.1097/01.ALC.0000052581.46630.C5

Curtis, M. A., Kam, M., Nannmark, U., Anderson, M. F., Axell, M. Z., Wikkelso, C., et al. (2007). Human neuroblasts migrate to the olfactory bulb via a lateral ventricular extension. Science 315, 1243-1249. doi: 10.1126/science.1136281

Daan, S., Beersma, D. G., and Borbély, A. A. (1984). Timing of human sleep: recovery process gated by a circadian pacemaker. Am. J. Physiol. 246, R161-R178. doi: $10.1126 /$ science. 1136281

Diekelmann, S., and Born, J. (2010). The memory function of sleep. Nat. Rev. Neurosci. 11, 114-126. doi: 10.1038/nrn2762

Dobrossy, M. D., Drapeau, E., Aurousseau, C., Le Moal, M., Piazza, P. V., and Abrous, D. N. (2003). Differential effects of learning on neurogenesis: learning increases or decreases the number of newly born cells depending on their birth date. Mol. Psychiatry 8, 974-982. doi: 10.1038/sj.mp.4001419

Duman, R. S., Heninger, G. R., and Nestler, E. J. (1997). A molecular and cellular theory of depression. Arch. Gen. Psychiatry 54, 597-606. doi: 10.1001/archpsyc.1997.01830190015002

Duman, R. S., Malberg, J., and Nakagawa, S. (2001). Regulation of adult neurogenesis by psychotropic drugs and stress. J. Pharmacol. Exp. Ther. 299, 401-407. doi: $10.1177 / 1073858414561303$ ů7.62

Easton, A., Meerlo, P., Bergmann, B. M., and Turek, W. T. (2004). The suprachiasmatic nucleus regulates sleep timing and amount in mice. Sleep 27, 1307-1318.

Eiland, M. M., Eiland, M. M., Ramanathan, L., Gulyani, S., Gilliland, M., Bergmann, B. M., et al. (2002). Increases in amino-cupric-silver staining of the supraoptic nucleus after sleep deprivation. Brain Res. 945, 1-8. doi: 10.1111/j.13652869.2012.01023.x

Eisch, A. J., Barrot, M., Schad, C. A., Self, D. W., and Nestler, E. J. (2000). Opiates inhibit neurogenesis in the adult rat hippocampus. Proc. Natl. Acad. Sci. U.S.A. 97, 7579-7584. doi: 10.1073/pnas.120552597

Enwere, E., Shingo, T., Gregg, C., Fujikawa, H., Ohta, S., and Weiss, S. (2004). Aging results in reduced epidermal growth factor receptor signaling, diminished olfactory neurogenesis, and deficits in fine olfactory discrimination. J. Neurosci. 24, 8354-8365. doi: 10.1523/JNEUROSCI.2751-04.2004

Eriksson, P. S., Perfilieva, E., Björk-Eriksson, T., Alborn, A., Nordborg, C., Peterson, D. A., et al. (1998). Neurogenesis in the adult human hippocampus. Nat. Med. 4, 1313-1317. doi: 10.1038/3305

Everson, C. A., and Crowley, W. R. (2004). Reductions in circulating anabolic hormones induced by sustained sleep deprivation in rats. Am. J. Physiol. 286, E1060-E1070. doi: 10.1152/ajpendo.00553.2003

Fuchs, E., and Gould, E. (2000). Mini-review: in vivo neurogenesis in the adult brain: regulation and functional implications. Eur. J. Neurosci. 12, 2211-2214. doi: 10.1046/j.1460-9568.2000.00130.x

Galea, L. A., and McEwen, B. S. (1999). Sex and seasonal changes in the rate of cell proliferation in the dentate gyrus of adult wild meadow voles. Neuroscience 89 955-964. doi: 10.1016/S0306-4522(98)00345-5

García-García, F., De la Herrán-Arita, A. K., Juárez-Aguilar, E., Regalado-Santiago, C., Millán-Aldaco, D., Blanco-Centurión, C., et al. (2011). Growth hormone improves hippocampal adult cell survival and counteracts the inhibitory effect of prolonged sleep deprivation on cell proliferation. Brain Res. Bull. 84, 252 257. doi: 10.1016/j.brainresbull.2011.01.003

Gobes, S. M., Zandbergen, M. A., and Bolhuis, J. J. (2010). Memory in the making: localized brain activation related to song learning in young songbirds. Proc. Biol. Sci. 277, 3343-3351. doi: 10.1098/rspb.2010.0870

Goel, N., Rao, H., Durmer, J. S., and Dnges, D. F. (2009). Neurocognitive consequences of sleep deprivation. Semin. Neurol. 29, 320-339. doi: 10.1055/s-00291237117

Goldman, S. A., and Nottebohm, F. (1983). Neuronal production, migration, and differentiation in a vocal control nucleus of the adult female canary brain. Proc. Natl. Acad. Sci. U.S.A. 80, 2390-2394. doi: 10.1073/pnas.80.8.2390

Gould, E., Beylin, A., Tanapat, P., Reeves, A., and Shors, T. J. (1999). Learning enhances adult neurogenesis in the hippocampal formation. Nat. Neurosci. 2, 260-265.

Gould, E., and Tanapat, P. (1999). Stress and hippocampal neurogenesis. Biol. Psychiatry 46, 1472-1479. doi: 10.1016/S0006-3223(99)00247-4

Graves, L., Pack, A. L., and Abel, T. (2001). Sleep and memory: a molecular perspective. Trends Neurosci. 24, 237-243. doi: 10.1016/S0166-2236(00)01744-6

Gross, C. G. (2000). Neurogenesis in the adult brain: death of a dogma. Neuroscience 1, 67-73. doi: 10.1038/35036235

Guzman-Marin, R., Bashir, T., Suntsova, N., Szymusiak, R., and McGinty, D. (2007a). Hippocampal neurogenesis is reduced by sleep fragmentation in the adult rat. Neuroscience 148, 325-333. doi: 10.1016/j.neuroscience.2007.05.030

Guzman-Marin, R., Suntsova, N., Bashir, T., Szymusiak, R., and McGinty, D. (2007b). Cell proliferation in the dentate gyrus of the adult rat fluctuates with the light-dark cycle. Neurosci. Lett. 422, 198-201. doi: 10.1016/j.neulet.2007. 06.022

Guzman-Marin, R., and McGinty, D. (2006). Sleep deprivation suppresses adult neurogenesis: clues to the role of sleep in brain plasticity. Sleep Biol. Rhythms 4, 27-34. doi: 10.1111/j.1479-8425.2006.00203.x

Guzman-Marin, R., Suntsova, N., Bashir, T., Nienhuis, R., Szymusiak, R., and McGinty, D. (2008). Rapid eye movement sleep deprivation contributes to 
reduction of neurogenesis in the hippocampal dentate gyrus of the adult rat. Sleep 31, 167-175.

Guzman-Marin, R., Suntsova, N., Methippara, M., Greiffenstein, R., Szymusiak, R., and McGinty, D. (2005). Sleep deprivation suppresses neurogenesis in the adult hippocampus of rats. Eur. J. Neurosci. 22, 2111-2116. doi: 10.1111/j.14609568.2005.04376.x

Guzmán-Marín, R., Suntsova, N., Stewart, D. R., Gong, H., Szymusiak, R., and McGinty, D. (2003). Sleep deprivation reduces proliferation of cells in the dentate gyrus of the hippocampus in rats. J. Physiol. 549, 563-571. doi: 10.1113/jphysiol.2003.041665

Guzman-Marin, R., Ying, Z., Suntsova, N., Szymusiak, R., Gomez-Pinilla, F., and McGinty, D. (2006). Suppression of hippocampal plasticity-related gene expression by sleep deprivation. J. Physiol. 575, 807-819. doi: 10.1113/jphysiol.2006.115287

Haack, M., Sanchez, E., and Mullington, J. M. (2007). Elevated inflammatory markers in response to prolonged sleep restriction are associated with increased pain experience in healthy volunteers. Sleep 30, 1145-1152.

Hairston, H. S., Little, M. T., Scanlon, M. D., Barakat, M. T., Palmer, T. D., and Sapolsky, R. M. (2005). Sleep restriction suppresses neurogenesis induced by hippocampal learning. J. Neurophysiol. 94, 4224-4233. doi: 10.1152/jn.00218.2005

Hastings, N. B., and Gould, E. (1999). Rapid extension of axons into the CA3 region by adult-generated granule cells. J. Comp. Neurol. 413, 146-154. doi: 10.1002/(SICI)1096-9861(19991011)413:1<146::AID-CNE10>3.0.CO;2-B

Heth, G., Nevo, E., and Todrank, J. (1996). Seasonal changes in urinary odors and in responses to them by blind subterranean mole rats. Physiol. Behav. 60, 963-968. doi: 10.1016/0031-9384(96)00077-7

Höglinger, G. U., Huppertz, H. J., Wagenpfeil, S., Andrés, M. V., Belloch, V., León, T., et al. (2014). Tideglusib reduces progression of brain atrophy in progressive supranuclear palsy in a randomized trial. Mov. Disord. 29, 479-487. doi: $10.1002 / \mathrm{mds} .25815$

Holmes, M. M., Galea, L. A., Mistlberger, R. E., and Kempermann, G. (2004). Adult hippocampal neurogenesis and voluntary running activity: circadian and dose-dependent effects. J. Neurosci. Res. 76, 216-222. doi: 10.1002/jnr.20039

Hu, H., Tomasiewicz, H., Magnuson, T., and Rutishauser, U. (1996). The role of polysialic acid in migration of olfactory bulb interneuron precursors in the subventricular zone. Neuron 16, 735-743. doi: 10.1016/S0896-6273(00) 80094-X

Imeri, L., and Opp, M. R. (2009). How (and why) the immune system makes us sleep. Nat. Rev. Neurosci. 10, 199-210. doi: 10.1038/nrn2576

Irwin, M. R., Wang, M., Campomayor, C. O., Collado-Hidalgo, A., and Cole, S. (2006). Sleep deprivation and activation of morning levels of cellular and genomic markers. Arch. Intern. Med. 166, 1756-1762. doi: 10.1001/archinte.166.16.1756

Ishida, A., Mutoh, T., Ueyama, T., Bando, H., Masubuchi, S., Nakahara, D., et al. (2005). Light activates the adrenal gland: timing of gene expression and glucocorticoid release. Cell Metab. 2, 297-307. doi: 10.1016/j.cmet.2005.09.009

Jacobs, B. L., van Praag, H., and Gage, F. H. (2000). Adult brain neurogenesis and psychiatry: a novel theory of depression. Mol. Psychiatry 5, 262-269. doi: 10.1038/sj.mp.4000712

Jin, K., Sun, Y., Xie, L., Batteur, S., Mao, X. O., Smelick, C., et al. (2003). Neurogenesis and aging: FGF-2 and HB-EGF restore neurogenesis in hippocampus and subventricular zone of aged mice. Aging Cell 2, 175-183. doi: 10.1046/j.1474-9728.2003.00046.x

Juneka, A., Rusakb, B., and Sembaa, K. (2010). Short-term sleep deprivation may alter the dynamics of hippocampal cell proliferation in adult rats. Neuroscience 170, 1140-1152. doi: 10.1016/j.neuroscience.2010. 08.018

Kaplan, M. S. (1977). Neurogenesis in the adult rat: electron microscopic analysis of light radioautographs. Science 197, 1092-1094. doi: 10.1126/science.887941

Kaplan, M. S. (1981). Neurogenesis in the 3-month-old rat visual cortex. J. Comp. Neurol. 195, 323-338. doi: 10.1002/cne.901950211

Kaplan, M. S. (1984). Mitotic neuroblasts in the 9-day-old and 11-month-old rodent hippocampus. J. Neurosci. 4, 1429-1441.

Kaplan, M. S. (1985). Formation and turnover of neurons in young and senescent animals: an electronmicroscopic and morphometric analysis. Ann. N. Y. Acad. Sci. 457, 173-192. doi: 10.1111/j.1749-6632.1985. tb20805.x
Keisler, A., and Willingham, J. A. (2007). Time of day accounts for overnight improvement in sequence learning. Learn. Mem. 14, 669-672. doi: $10.1101 / \mathrm{lm} .751807$

Kempermann, G. (2002). Regulation of adult hippocampal neurogenesis implications for novel theories of major depression. Bipolar Disord. 4, 17-33. doi: 10.1034/j.1399-5618.2002.40101.x

Kempermann, G., and Gage, F. H. (2002). Genetic influence on phenotypic differentiation in adult hippocampal neurogenesis. Brain Res. Dev. Brain Res. 134, 1-12. doi: 10.1016/S0165-3806(01)00224-3

Kempermann, G., Kuhn, H. G., and Gage, F. H. (1997). More hippocampal neurons in adult mice living in an enriched environment. Nature 386, 493-495. doi: $10.1038 / 386493 \mathrm{a} 0$

Kochman, L. J., Weber, E. T., Fornal, C. A., and Jacobs, B. L. (2006). Circadian variation in mouse hippocampal cell proliferation. Neurosci. Lett. 406, 256-259. doi: 10.1016/j.neulet.2006.07.058

Kornack, D. R., and Rakic, P. (1999). Continuation of neurogenesis in the hippocampus of the adult macaque monkey. Proc. Natl. Acad. Sci. U.S.A. 96, 5768-5773. doi: 10.1073/pnas.96.10.5768

Krueger, J. M., Rector, D. M., Roy, S., Van Dongen, H. P., Belenky, G., and Panksepp, J. (2008). Sleep as a fundamental property of neuronal assemblies. Nat. Rev. Neurosci. 9, 910-919. doi: 10.1038/nrn2521

Kuhn, H. G., Dickinson-Anson, H., and Gage, F. H. (1996). Neurogenesis in the dentate gyrus of the adult rat: age-related decrease of neuronal progenitor proliferation. J. Neurosci. 16, 2027-2033.

Lavenex, P., Steele, M. A., and Jacobs, L. F. (2000). The seasonal pattern of cell proliferation and neuron number in the dentate gyrus of wild adult eastern grey squirrels. Eur. J. Neurosci. 12, 643-648. doi: 10.1046/j.1460-9568.2000.00949.x

Leuner, B., Gould, E., and Shors, T. J. (2006). Is there a link between adult neurogenesis and learning? Hippocampus 16, 216-224. doi: 10.1002/hipo.20153

Lim, D. A., Tramontin, A. D., Trevejo, J. M., Herrera, D. G., Garcia-Verdugo, J. M., and Alvarez-Buylla, A. (2000). Noggin antagonizes BMP signaling to create a niche for adult neurogenesis. Neuron 28, 713-726. doi: 10.1016/S08966273(00)00148-3

Mahajan, M. A., Das, S., Zhu, H., Tomic-Canic, M., and Samuels, H. H. (2004). The nuclear hormone receptor coactivator NRC is a pleiotropic modulator affecting growth, development, apoptosis, reproduction, and wound repair. Mol. Cell. Biol. 24, 4994-5004. doi: 10.1128/MCB.24.11.4994-5004.2004

Malberg, J. E., Eisch, A. J., Nestler, E. J., and Duman, R. S. (2000). Chronic antidepressant treatment increases neurogenesis in adult rat hippocampus. J. Neurosci. 20, 9104-9110.

Manganas, L. N., Zhang, X., Li, Y., Hazel, R. D., Smith, S. D., Wagshul, M. E., et al. (2007). Magnetic resonance spectroscopy identifies neural progenitor cells in the live human brain. Science 318, 980-985. doi: 10.1126/science.1147851

Maywood, E. S., Reddy, A. B., Wong, G. K., O’Neill, J. S., O’Brien, J. A., McMahon, D. G., et al. (2006). Synchronization and maintenance of timekeeping in suprachiasmatic circadian clock cells by neuropeptidergic signaling. Curr. Biol. 16, 599-605. doi: 10.1016/j.cub.2006.02.023

Meerlo, P., Mistlberger, R. E., Jacobs, B. L., Heller, C., and McGinty, D. (2009). New neurons in the adult brain: the role of sleep and consequences of sleep loss. Sleep Med. Rev. 13, 187-194. doi: 10.1016/j.smrv.2008.07.004

Ming, G. L., and Song, H. (2005). Adult neurogenesis in the mammalian central nervous system. Annu. Rev. Neurosci. 28, 223-250. doi: 10.1146/annurev.neuro.28.051804.101459

Mirescu, C., Peters, J. D., Noiman, L., and Gould, E. (2006). Sleep deprivation inhibits adult neurogenesis in the hippocampus by elevating glucocorticoids. Proc. Natl. Acad. Sci. U.S.A. 103, 19170-19175. doi: 10.1073/pnas.0608644103

Monje, M. L., Toda, H., and Palmer, T. D. (2003). Inflammatory blockade restores adult hippocampal neurogenesis. Scienc 302, 1760-1765. doi: 10.1126/science. 1088417

Moore, R. Y., Speh, J. C., and Leak, R. K. (2002). Suprachiasmatic nucleus organization. Cell Tissue Res. 309, 89-98. doi: 10.1007/s00441-002-0575-2

Moser, M. B., and Moser, E. I. (1998). Functional differentiation in the hippocampus. Hippocampus 8, 608-619. doi: 10.1002/(SICI)10981063(1998)8:6<608::AID-HIPO3>3.0.CO;2-7

Mueller, A. D., Mear, R. J., and Mistlberger, R. E. (2011). Inhibition of hippocampal neurogenesis by sleep deprivation is independent of circadian disruption and melatonin suppression. Neuroscience 193, 170-181. doi: 10.1016/j.neuroscience.2011.07.019 
Mueller, A. D., Meerlo, P., McGinty, D., and Mistlberger, R. E. (2013). "Sleep and adult neurogenesis: implications for cognition and mood," in Current Topics in Behavioral Neurosciences, eds M. A. Geyer, B. A. Ellenbroek, C. A. Marsden, and Th.R.E. Barnes (Heidelberg: Springer), 1-31.

Mueller, A. D., Pollock, M. S., Lieblich, S. E., Epp, J. R., Galea, L. A., and Mistlberger, R. E. (2008). sleep deprivation can inhibit adult hippocampal neurogenesis independent of adrenal stress hormones. Am. J. Physiol. Regul. Integr. Comp. Physiol. 294, R1693-R1703. doi: 10.1152/ajpregu.00858.2007

Murase, S., and Horwitz, A. F. (2002). Deleted in colorectal carcinoma and differentially expressed integrins mediate the directional migration of neural precursors in the rostral migratory stream. J. Neurosci. 22, 3568-3579.

Murillo-Rodríguez, E., Arias-Carrión, O., Sanguino-Rodríguez, K., GonzálezArias, M., and Haro, R. (2009). Mechanisms of sleep-wake cycle modulation. CNS Neurol. Disord. Drug Targets 8, 245-253. doi: 10.1016/j.expneurol.2011.02.020

Neylan, T. C., Mueller, S. G., Wang, Z., Metzler, T. J., Lenoci, M., and Truran, D. (2010). Insomnia severity is associated with a decreased volume of the CA3/dentate gyrus hippocampal subfield. Biol. Psychiatry 494-496. doi: 10.1016/j.neuroscience.2011.07.019

Nibuya, M., Morinobu, S., and Duman, R. S. (1995). Regulation of BDNF and trkB mRNA in rat brain by chronic electroconvulsive seizure and antidepressant drug treatments. J. Neurosci. 15, 7539-7547.

Nilsson, M., Perfilieva, E., Johansson, U., Orwar, O., and Eriksson, P. S. (1999). Enriched environment increases neurogenesis in the adult rat dentate gyrus and improves spatial memory. J. Neurobiol. 39, 569-578. doi: 10.1002/(SICI)10974695(19990615)39:4<569::AID-NEU10>3.0.CO;2-F

Nissen, C., Kloepfer, C., Nofzinger, E., Feige, B., Voderholzer, U., and Riemann, D. (2006). Impaired sleep-related memory consolidation in primary insomnia: a pilot study. Sleep 29, 1068-1073.

Nofzinger, E. A., Nissen, C., Germain, A., Moul, D., Hall, M., Price, J. C., et al. (2006). Regional cerebral metabolic correlates of WASO during NREMS sleep in insomnia. J. Clin. Sleep Med. 2, 316-322.

Novati, A., Hulshof, H. J., Koolhaas, J. M., Lucassenc, P. J., and Meerlo, P. (2011). Chronic sleep restriction causes a decrease in hippocampal volume in adolescent rats, which is not explained by changes in glucocorticoid levels or neurogenesis. Neuroscience 190, 145-155. doi: 10.1016/j.neuroscience.2011.06.027

Novati, A., Roman, V., Cetin, T., Hagewoud, R., Boer, J. A., Luiten, P. G., et al. (2008). Chronically restricted sleep leads to depression-like changes in neurotransmitter receptor sensitivity and neuroendocrine stress reactivity in rats. Sleep 31, 1579-1585.

Nowakowski, R. S., Lewin, S. B., and Miller, M. W. (1989). Bromodeoxyuridine immunohistochemical determination of the lengths of the cell cycle and the DNA-synthetic phase for an anatomically defined population. J. Neurocytol. 18, 311-318. doi: 10.1007/BF01190834

Opp, M. R. (2009). Sleeping to fuel the immune system: mammalian sleep and resistance to parasites. BMC Evol. Biol. 9:8. doi: 10.1186/1471-2148-9-8

Orban, P., Rauchs, G., Balteau, E., Degueldre, C., Luxen, A., Maquet, P., et al. (2006). Sleep after spatial learning promotes covert reorganization of brain activity. Proc. Natl. Acad. Sci. U.S.A. 103, 7124-7129. doi: 10.1073/pnas. 0510198103

Ormerod, B. K., and Galea, L. A. (2003). Reproductive status influences the survival of new cells in the dentate gyrus of adult male meadow voles. Neurosci. Lett. 346, 25-28. doi: 10.1016/S0304-3940(03)00546-9

Peigneux, P., Laureys, S., Fuchs, S., Collette, F., Perrin, F., Reggers, J., et al. (2004). Are spatial memories strengthened in the human hippocampus during slow wave sleep? Neuron 44, 535-545. doi: 10.1016/j.neuron.2004.10.007

Price, J., Turner, D., and Cepko, C. (1987). Lineage analysis in the vertebrate nervous system by retrovirus-mediated gene transfer. Proc. Natl. Acad. Sci. U.S.A. 84, 156-160. doi: 10.1073/pnas.84.1.156

Radley, J. J., and Jacobs, B. L. (2002). 5-HT1A receptor antagonist administration decreases cell proliferation in the dentate gyrus. Brain Res. 955, 264-267. doi: 10.1016/S0006-8993(02)03477-7

Rasch, B., Pommer, J., Diekelmann, S., and Born, J. (2008). Pharmacological REM sleep suppression paradoxically improves rather than impairs skill memory. Nat. Neurosci. 12, 396-397. doi: 10.1038/nn.2206

Rector, D. M., Topchiy, I. A., Carter, K. M., and Rojas, M. J. (2005). Local functional state differences between rat cortical. Brain Res. 1047, 45-55. doi: 10.1016/j.brainres.2005.04.002
Rickard, T. C., Cai, D. J., Rieth, C. A., Jones, J., and Ard, M. C. (2008). Sleep does not enhance motor sequence learning. J. Exp. Psychol. Learn. Mem. Cogn. 34, 834-842. doi: 10.1037/0278-7393.34.4.834

Riemann, D., Voderholzer, U., Spiegelhalder, K., Psych, D., Hornyak, M., Buysse, D. J., et al. (2007). Chronic insomnia and MRI-measured hippocampal volume: a pilot study. Sleep 30, 955-985.

Roman, V., van der Borght, K., Leemburg, S., van der Zee, E. A., and Meerlo, P. (2005). Sleep restriction by forced activity reduces hippocampal cell proliferation. Brain Res. 1065, 53-59. doi: 10.1016/j.brainres.2005.10.020

Roy, S., Krueger, J. M., Rector, D. M., and Wan, Y. (2008). A Network model for activity-dependent sleep regulation. J. Theor. Biol. 253, 462-468. doi: 10.1016/j.jtbi.2008.03.033

Ruehland, W. R., O'Donoghue, F. J., Pierce, R. J., Thornton, A. T., Singh, P., Copland, J. M., et al. (2011). The 2007 AASM recommendations for EEG electrode placement in polysomnography: impact on sleep and cortical arousal scoring. Sleep 34, 73-81.

Saghatelyan, A., Chevigny, A., Schachner, M., and Lledo, P. M. (2004). Tenascin$\mathrm{R}$ mediates activitydependent recruitment of neuroblasts in the adult mouse forebrain. Nat. Neurosci. 7, 347-356. doi: 10.1038/nn1211

Sahay, A., and Hen, R. (2007). Adult hippocampal neurogenesis in depression. Nat. Neurosci. 10, 1110-1115. doi: 10.1038/nn1969

Sahu, S., Kauser, H., Ray, K., Kishore, K., Kumar, S., and Panjwani, U. (2013). Caffeine and modafinil promote adult neuronal cell proliferation during $48 \mathrm{~h}$ of total sleep deprivation in rat dentate gyrus. Exp. Neurol. 248, 470-481. doi: 10.1016/j.expneurol.2013.07.021

Sakamotoa, M., Imayoshia, I., Ohtsukaa, T., Yamaguchie, M., Morie, K., and Kageyamaa, R. (2011). Continuous neurogenesis in the adult forebrain is required for innate olfactory. Proc. Natl. Acad. Sci. U.S.A. 108, 8479-8484. doi: 10.1073/pnas.1018782108

Sanes, J. R., Rubenstein, J. L., and Nicolas, J. F. (1986). Use of a recombinant retrovirus to study post-implantation cell lineage in mouse embryos. EMBO J. 5, 3133-3142.

Saper, C. B., Chou, T. C., and Scammell, T. E. (2001). The sleep switch: hypothalamic control of sleep and wakefulness. Trends Neurosci. 24, 726-731. doi: 10.1016/S0166-2236(00)02002-6

Scharfman, H., Goodman, J., Macleod, A., Phani, S., Antonelli, C., and Croll, S. (2005). Increased neurogenesis and the ectopic granule cells after intrahippocampal BDNF infusion in adult rats. Exp. Neurol. 192, 348-356. doi: 10.1016/j.expneurol.2004.11.016

Shapiro, E. M., Gonzalez-Perez, O., García-Verdugo, J. M., Alvarez-Buylla, A., and Koretsky, A. P. (2006). Magnetic resonance imaging of the migration ofneuronal precursors generated in the adult rodent brain. Neuroimage 32, 1150-1157. doi: 10.1016/j.neuroimage.2006.04.219

Sheth, B. R., Nguyen, N., and Janvelyan, D. (2009). Does sleep really influence face recognition memory? PLOS ONE 4:e5496. doi: 10.1371/journal.pone. 0005496

Sidman, R. L., Miale, I. L., and Feder, N. (1959). Cell proliferation and migration in the primitive ependymal zone; an autoradiographic study of histogenesis in the nervous system. Exp. Neurol. 1, 322-333. doi: 10.1016/0014-4886(59) 90024-X

Siegel, J. M. (2001). The REM sleep-memory consolidation hypothesis. Science 294, 1058-1063. doi: 10.1126/science. 1063049

Siegel, J. M. (2009). Sleep viewed as a state of adaptive inactivity. Nat. Rev. Neurosci. 10, 747-753. doi: 10.1038/nrn2697

Smulders, T. V., Shiflett, M. W., Sperling, A. J., and DeVoogd, T. J. (2000). Seasonal changes in neuron numbers in the hippocampal formation of a food-hoarding bird: the black-capped chickadee. J. Neurobiol. 44, 414-22. doi: 10.1002/10974695(20000915)44

Song, S., Howard, J. H., and Howard, D. V. (2007). Sleep does not benefit probabilistic motor sequence learning. J. Neurosci. 27, 12475-12483. doi: 10.1523/JNEUROSCI.2062-07.2007

Sportiche, N., Suntsova, N., Methippara, M., Bashir, T., Mitrani, B., Szymusiak, R., et al. (2010). Sustained sleep fragmentation results in delayed changes in hippocampal-dependent cognitive function associated with reduced dentate gyrus neurogenesis. Neuroscience 170, 247-258. doi: 10.1016/j.neuroscience.2010.06.038

Stickgold, R. (2005). Sleep-dependent memory consolidation. Nature 437, 1272 1278. doi: 10.1038 /nature 04286 
Stickgold, R., and Walker, M. P. (2005). Memory consolidation and reconsolidation: what is the role of sleep? Trends Neurosci. 28, 408-415. doi: 10.1016/j.tins.2005.06.004

Takahashi, J., Palmer, T. D., and Gage, F. H. (1998). Retinoic acid and neurotrophins collaborate to regulate neurogenesis in adult-derived neural cell cultures. J. Neurobiol. 38, 65-81. doi: 10.1002/(SICI)1097-4695(199901)38

Takase, L. F., Fornal, C. A., and Jacobs, B. L. (2009). Effects of the hypnotic drug zolpidem on cell proliferation and survival in the dentate gyrus of young and old rats. Brain Res. 1259, 26-31. doi: 10.1016/j.brainres.2008.12.049

Tamai, S., Sanada, K., and Fukada, Y. (2008). Time-of-Day-Dependent enhancement of adult neurogenesis in the hippocampus. PLOS ONE 3:e3835. doi: 10.1371/journal.pone.0003835

Tanapat, P., Hastings, N. B., Reeves, A. J., and Gould, E. (1999). Estrogen stimulates a transient increase in the number of new neurons in the dentate gyrus of the adult female rat. J. Neurosci. 19, 5792-5801.

Tramontin, A. D., and Brenowitz, E. A. (2000). Seasonal plasticity in the adult brain. Trends Neurosci. 23, 251-258. doi: 10.1016/S0166-2236(00)01558-7

Trejo, J. L., Carro, E., and Torres-Aleman, I. (2001). Circulating insulin-like growth factor I mediates exercise-induced increases in the number of new neurons in the adult hippocampus. J. Neurosci. 21, 1628-1634.

Tung, A., Takase, L., Fornal, C., and Jacobs, B. (2005). Effects of sleep deprivation and recovery sleep upon cell proliferation in adult rat dentate gyrus. Neuroscience 134, 721-723. doi: 10.1016/j.neuroscience.2005.06.008

van der Borght, K., Ferrari, F., Klauke, K., Roman, V., Havekes, R., Sgoifo, A., et al. (2006). Hippocampal cell proliferation across the day: increase by running wheel activity but no effect of sleep and wakefulness. Behav. Brain Res. 167, 36-41. doi: 10.1016/j.bbr.2005.08.012

van Praag, H., Kempermann, G., and Gage, F. H. (1999). Running increases cell proliferation and neurogenesis in the adult mouse dentate gyrus. Nat. Neurosci. 2, 266-270. doi: 10.1038/6368

van Praag, H., Schinder, A. F., Christie, B. R., Toni, N., Palmer, T. D., and Gage, F. H. (2002). Functional neurogenesis in the adult hippocampus. Nature 415, 1030-1034. doi: 10.1038/4151030a

Walton, J. C., Pyter, L. M., Weil, Z. M., and Nelson, R. J. (2012). Photoperiod mediated changes in olfactory bulb neurogenesis and olfactory behavior in male white-footed mice (Peromyscus leucopus). PLoS ONE 8:e42743. doi: 10.1371/journal.pone.0042743

Wang, S., Scott, B. W., and Wojtowicz, J. M. (2000). Heterogenous properties of dentate granule neurons in the adult rat. J. Neurobiol. 42, 248-257. doi: 10.1002/(SICI)1097-4695(20000205)42

Wang, W., Pan, Y. W., Wietecha, T., Zou, J., Abel, G. M., Kuo, C. T., et al. (2013). Extracellular signal-regulated kinase 5 (ERK5) mediates prolactin-stimulated adult neurogenesis in the subventricular zone and olfactory bulb. J. Biol. Chem. 288, 2623-2631. doi: 10.1074/jbc.M112. 401091

Warner-Schmidt, J. L., and Duman, R. S. (2007). VEGF is an essential mediator of the neurogenic and behavioral actions of antidepressants. Proc. Natl. Acad. Sci. U.S.A. 104, 4647-4652. doi: 10.1073/pnas. 0610282104

Yuan, T. F., and Arias-Carrion, O. (2011). Adult neurogenesis in the hypothalamus: evidence, functions, and implications. CNS Neurol. Disord. Drug Targets 10, 433-439. doi: 10.2174/187152711795563985

Yuan, T. F., Li, J., Ding, F., and Arias-Carrion, O. (2014). Evidence of adult neurogenesis in non-human primates and human. Cell Tissue Res. 358, 17-23. doi: 10.1007/s00441-014-1980-Z

Zucconi, G. G., Cipriani, S., Balgkouranidou, I., and Scattoni, R. (2006). 'One night' sleep deprivation stimulates hippocampal neurogenesis. Brain Res. Bull. 69, 375-381. doi: 10.1016/j.brainresbull.2006.01.009

Conflict of Interest Statement: The authors declare that the research was conducted in the absence of any commercial or financial relationships that could be construed as a potential conflict of interest.

Copyright (C) 2015 Fernandes, Rocha, Rocha, Herrera-Solís, Salas-Pacheco, GarcíaGarcía, Murillo-Rodríguez, Yuan, Machado and Arias-Carrión. This is an openaccess article distributed under the terms of the Creative Commons Attribution License (CC BY). The use, distribution or reproduction in other forums is permitted, provided the original author(s) or licensor are credited and that the original publication in this journal is cited, in accordance with accepted academic practice. No use, distribution or reproduction is permitted which does not comply with these terms. 